\title{
Review Article \\ The Tsim Tsoum Approaches for Prevention of Cardiovascular Disease
}

\author{
R. B. Singh, Fabien DeMeester, and Agnieska Wilczynska
}

Tsim Tsoum Institute, Ul. Golebia 2, 31-007 Krakow, Poland

Correspondence should be addressed to R. B. Singh, rbs@tsimtsoum.net

Received 27 March 2010; Accepted 15 May 2010

Academic Editor: Hector Ventura

Copyright () 2010 R. B. Singh et al. This is an open access article distributed under the Creative Commons Attribution License, which permits unrestricted use, distribution, and reproduction in any medium, provided the original work is properly cited.

The Tsim Tsoum Concept means that humans evolved on a diet in which nature recommends to ingest fatty acids in a balanced ratio (polyunsaturated $(\mathrm{P})$ : $\operatorname{saturated}(\mathrm{S})=\mathrm{w}-6: \mathrm{w}-3=1: 1$ ) as part of dietary lipid pattern where monounsaturated fatty acids(MUFA) is the major fatty acid(P:M:S=1:6:1) in the background of other dietary factors; antioxidants, vitamins, minerals and fiber as well as physical activity and low mental stress. Several hundred years ago, our diet included natural foods; fruits, vegetables, green vegetables, seeds, eggs and honey. Fish, and wild meat were also available to pre-agricultural humans which shaped modern human genetic nutritional requirement. Cereal grains (refined), and vegetable oils that are rich in w-6 fatty acids are relatively recent addition to the human diet that represent dramatic departure from those foods to which we are adapted. Excess of linoleic acid, trans fatty acids (TFA), saturated and total fat as well as refined starches and sugar are proinflammatory. Low dietary MUFA and n-3 fatty acids and other long chain polyunsarurated fatty acids (LCPUFA) are important in the pathogenesis of metabolic syndrome. Increased sympathetic activity with greater secretion of neurotransmitters in conjunction of underlying long chain PUFA deficiency, and excess of proinflammatory nutrients, may damage the neurons via proinflammatory cytokines, in the ventromedial hypothalamus and insulin receptors in the brain.Since, $30-50 \%$ of the fatty acids in the brain are LCPUFA, especially omega-3 fatty acids, which are incorporated in the cell membrane phospholipids, it is possible that their supplementation may be protective.Blood lipid composition does reflect one's health status: (a) circulating serum lipoproteins and their ratio provide information on their atherogenicity to blood vessels and (b) circulating plasma fatty acids, such as w-6/w-3 fatty acid ratio, give indication on proinflammatory status of blood vessels, cardiomyocytes, liver cells and neurones; (a) and (b) are phenotype-related and depend on genetic, environmental and developmental factors. As such, they appear as universal markers for holistic health and these may be important in the pathogenesis of cardiovascular diseases and cancer, which is the main consideration of Tsim Tsoum concept.

\section{Introduction}

The epidemic of cardiovascular disease (CVD), diabetes, and cancer, in the western world and in middle income countries, indicates major increases in the incidence of generalized atherosclerosis and the total burden of CVD due to changes in the environmental factors [1-6]. Maladaptation, genetic predisposition, environmental, dietary, and lifestyle factors are the predominant contributors of CVD leading to the development of these problems [1-5]. It has been suggested that lifestyle factors such as physical inactivity and unhealthy and unbalanced nutritional consumption of excess calories, simple refined carbohydrates with a high glycemic index and load of high saturated fat (SF), high trans fatty acids (TFA), high n-6 fatty acids, and lack of monounsaturated fatty acids (MUFA) and n-3 fatty acids in the diet and reduced exercise, can cause genetic damage, contributing to the escalating rates of obesity and mortality due to CVD [39]. Hypertension and stroke as well as coronary artery disease (CAD), diabetes, and cancers have become a major cause of morbidity and mortality in Asia [10-13]. The obesity and CVD are contributing to major economic and public health concerns and problems that mandate aggressive, urgent, and dedicated identification, prevention, treatment, and education of public, private, and governmental agencies in both developed and middle economies [4-7]. 
Adverse effects of the diet were known to Indians from the ancient times, which is evident from the following verse from an ancient scripture Bhagwad gita. "Foods which are bitter, acid, salted, burnt, fried, and punent, give rise to pain, mental stress, and diseases" (3100BC). Charaka (600BC), a great physician of India, knew about the role of diet and lifestyle in the pathogenesis of heart attack, which would be clear from the following verse. "Heart attack is born by the intake of fatty meals, overeating, excess of sleep, lack of exercise, and anxiety". Charaka Sutra, 600BC. While Charak was suppose to live in Taxila University in north of India and was a Brahman physician, Sushruta was a surgeon from Vishwamitra family from Varanasi. In mahabharata, he is represented as a son of that royal sage. The garuda puranam places Divodasa as 4 th in descent from Dhanavantari, the first propounder of the medical sciences upon earth, whereas the sushruta samhita describes both as same persons. Sushruta who was a surgeon, gave a more clear description of atheroscerosis or madroga; "Excess intake of fatty foods and lack of exercise causes obesity and narrowing of the channels taking blood to the heart. It is useful to use guggul, triphala and silajit in the treatment". These herbs are known to have high content of antioxidant flavonoids, vitamins and minerals as well as fibres.

In the 7th century $\mathrm{BC}$, one Chinese physician proposed that "increased consumption of salt may cause hardening of the pulse". About 2000 years ago from now (1st century), Confucius, the Chinese philosopher taught his students, "the higher the quality of foods, the better, and never rely upon the delicacy of cooking". Thus, a dietary guideline based on experience, observation, and thinking was given as; "cereals, the basic, fruits the subsidiary, meat the beneficial, and vegetable the supplementary". Therefore, according to WHO experts 1990, the concept of eating a diet high in animal foods and preference for meat and greasy foods was shaped in China. However, possibly the meat was rich in w-3 fatty acids, and the total fat intake remained within desirable limits and did not exceed as in the west. However, these diatary patterns were associated with enormous physical activity and sports such as hunting and also possibly meditation due to introduction of Budhism, causing possibly no significant problem of CVDs during that period. Moreover, the meat may have been from the running animals which has useful fatty acid composition. It seems that Columbus diet and lifestyle was known to Indians and Chinese from the ancient period.

\section{Causes of Mortality}

Vascular variability disorders (VVDs) that are commonly called cardiovascular diseases (CVD) are number one causes of death globally and would be projected to remain the leading cause of death. According to WHO estimates, 17.5 million people died from VVDs in 2005, representing 30\% of all global deaths. Coronary artery disease was the cause of death, among 7.6 million and 5.7 million deaths were due to stroke [1-4]. Majority of these deaths (80\%) occurred in low and middle income countries. The total world population in 2007 was 6.6 billion including 1.3 billion South East Asians, which would increase to 7.9 billion and 1.6 billion respectively by the year 2025 . Adult population aged 20-79 years, in the world was 4.1 billion, including 770 million South East Asians, in the year 2007, which would increase to 5.2 billion and 1083 million respectively by the year 2025. In one recent study [5], all causes of mortality were infectious diseases $(41.1 \%, n=915)$ such as tuberculosis, pneumonia, chronic obstructive pulmonary disease, diarrhea/dyssentary, hepatitis B, and inflammatory brain infections as the commonest cause of deaths in the urban population of north India. The second most common causes of deaths were circulatory diseases $(29.1 \%, n=$ $646)$ including heart attacks $(10.0 \%)$, stroke $(7.8 \%)$, valvular heart disease $(7.2 \%, n=160)$, sudden cardiac death, and inflammatory cardiac disease, each $(2.0 \%, n=44)$. Malignant neoplasm $(5.8 \%, n=131)$, injury $(14.0 \%, n=$ 313 ) including accidents, fire, and falls, and poisonings were also quite common causes of death. Miscellaneous causes of deaths were noted in 9.1\%, $(n=202)$ death records, including diabetes mellitus $(2.2 \%, 49)$, suicides $(1.8 \%, n=$ $41)$, congenital anomalies (1.0, $n=37)$, dental caries infections (1.9, $n=42)$, and burns $(1.3 \%, n=33)$. Pregnancy and perinatal causes $(0.72 \%, n=15)$ were not commonly recorded in our study. Circulatory diseases as the cause of mortality were significantly more common among higher social classes 1-3 than in lower social classes 4 and 5 who died more often, due to infections. Heart attacks, stroke, hypertension, diabetes, and obesity were significantly more common among higher social classes 1-3 compared to class 3 and 4 but tobacco intake showed only minor differences in various classes.

According to Registrar General of India [7], in the year 1994 to 1998 , trends indicate that there has been a significant decline of proportionate deaths from infectious diseases from $22 \%$ to $16 \%$. However, mortality from cardiovascular diseases (CVD) increased from $21 \%$ to $25 \%$ which is lower than death rate of 29.1 reported by Singh et al. in 2005 [5]. In Chennai, Gajalakshmi et al. [7] performed verbal autopsy among 48,357 adults aged 25-69 years. Deaths due to vascular diseases were $38.6 \%(n=18,680)$, followed by cancer $(8.7 \%)$, tuberculosis $(5.8 \%)$, and respiratory causes (3.5\%). In another larger sample consisting of 150,000 subjects, there were 1,354 deaths in the first year follow up and verbal autopsy revealed that circulatory diseases as the cause of death were noted in 34\% men and 30\% women. Mohan et al. studied the mortality rates due to diabetes in selected urban population from south India [9] among 1399 subjects (respondents 1262). During a median follow up of 6 years, deaths were significantly greater among diabetics compared to nondiabetics (18.9 versus 5.3 per 1000 person years, $P=.004)$. Mortality due to CVD were $52.9 \%$ among diabetics and 24.2 among nondiabetics. It is clear that the burden of CVD and diabetes appears to be quite significant in India indicating urgency for prevention program [411]. The higher risk of CAD mortality is not explained by conventional risk factors common among Indian immigrants to industrialized countries $[12,13]$. Indian Society of Hypertension and International College of Nutrition and 
other experts have proposed guidelines for prevention of CVD and diabetes in Indians and Asians, which are being used for public education by the health workers. Social class is a determinant of mortality including cardiovascular mortality $[4,5]$. It thus seems logical to examine whether differences in nutritional intake exist between the social classes, which could explain part of the existing differences in mortality due to CVD, diabetes, and cancers [4-13].

About one fifth of the adult population in developing countries and one fourth in industrialized countries, may have CVD and diabetes [3-6]. The prevalence of diabetes and prediabetes were about 6\% each in the year 2007 in South East Asia, indicating that 46.5 million subjects above 20 years had this problem which would be doubled by the year 2025. Similar targets have been calculated for CAD. The burden of hypertension would be 4 -fold greater compared to diabetes. In various studies, the prevalence of hypertension $(>140 / 90 \mathrm{mmHg}$ ) has been reported to be $22-30 \%$ in India among urban subjects above 20 years of age. The prevalence of CAD varies between $8 \%$ to $14 \%$ in various cities of India. In rural population, the prevalences of diabetes, hypertension, and CAD is 2-3 fold lower compared to urban subjects. Dietary intake of total fat amounts to $25 \%-45 \%$ in developed countries and $15 \%-35 \%$ of total energy in developing countries [7]. Most of the dietary fatty acids are derived from meats, oils, and dairy products, resulting in marked increase in saturated and w-6 fatty acids but relatively modest of monounsaturated fatty acids (MUFA) and long-chain polyunsaturated fatty acids (PUFAs) [10] particularly w-3 fatty acids. Refining of vegetable oils has been a major cause for increased consumption of w- 6 fatty acids and hydrogenation of these oils caused greater intake of TFA, that may be the cause of mitochondrial damage in the related organs: endothelial cells, cardiomyocytes, smooth muscle cells, neurons, beta cells, and liver, causing mitochondrial damage, leading to increased prevalence of CVD, diabetes, cancers, and neurodegenerative diseases in most countries of the world [1-9]. The increase in CVD morbidity and mortality may be related to changes in diet and w-3 fatty acid consumption (Tables 1, 2, 3, 4 and 5). While Japan, Greenland, and Mediterranean countries consuming high w-3 fatty acid have lower CVD mortality, death rates are much higher in the northern Europe, USA, and South Asia consuming high w-6 and low w-3 diets (Tables 4 and 5).

\section{The Evolution of Diet and the Columbus Concept}

There have been marked changes in the food supply with the development of agriculture about 10,000 years ago from now. However, only nonsignificant change in our genes occurred, during the past 10 century, due to presence of $\mathrm{w}-3$ fatty acids, vitamins, and minerals in the diet. The spontaneous mutation rate for nuclear DNA is estimated at $0.5 \%$ per million years. Hence, over the past 10,000 years there has been time for very little change in our genes, possibly $0.005 \%$. Our genes appear to be similar to the genes of our ancestors
TABLE 1: Food and nutrient intake among hunter-gatherer and western population.

\begin{tabular}{|c|c|c|}
\hline $\begin{array}{l}\text { Food and } \\
\text { nutrient }\end{array}$ & Hunter-gatherer & $\begin{array}{c}\text { Western } \\
\text { population }\end{array}$ \\
\hline Energy density & Low & High \\
\hline Protein & High & Low-moderate \\
\hline Animal & High & Low-moderate \\
\hline Vegetable & Very low & Low-moderate \\
\hline Carbohydrate & $\begin{array}{c}\text { Low-moderate (slowly } \\
\text { absorbed) }\end{array}$ & $\begin{array}{c}\text { Moderate-rapidly } \\
\text { absorbed }\end{array}$ \\
\hline Fiber & High & Low \\
\hline Fat & Low & High \\
\hline Animal & Low & High \\
\hline Vegatable & Very low & High \\
\hline Total w-3 & High ( $2.3 \mathrm{~g} /$ day $)$ & Low (0.2 g/day) \\
\hline Ratio w-6:w-3 & Low 2.4 & High 15-20 \\
\hline $\begin{array}{l}\text { Vitamins and } \\
\text { minerals }\end{array}$ & High & low \\
\hline
\end{tabular}

Modified from Simopoulos 2003 [14].

during the Paleolithic period 40,000 years ago, the time when our genetic profile was established. Man appears to live in a nutritional environment which completely differs from that for which our genetic constitution was selected. However, it was only during the last $100-160$ years that dietary intakes have changed significantly, causing increased intake of saturated fatty acids (SFA) and linoleic acid, and decrease in w-3 fatty acids, from grain-fed cattle, tamed at farm houses, rather than meat from running animals. There is a marked decrease in the intake of vitamins and antioxidants. The food and nutrient intake among huntergatherers and during Paleolithic period are given in Tables $1-3$. There is a marked reduction in consumption of $w-3$ fatty acids, vitamins, minerals, and proteins and significant increase in the intakes of carbohydrates, (mainly refined) fat (saturated, trans fat, and linoleic acid), and salt compared to Paleolithic period.

The Columbus concept of diet means that humans evolved on a diet that was low in saturated fat and the amount of w-3 and w-6 fatty acids was quite equal [15]. Nature recommends to ingest fatty acids in a balanced ratio (polyunsaturated: saturated $=\mathrm{w}-6: \mathrm{w}-3=1: 1$ ) as part of dietary lipid pattern in which monounsaturated fatty acids is the major fat $(\mathrm{P}: \mathrm{M}: \mathrm{S}=1: 6: 1)$. These ratios represent the overall distribution of fats in a natural untamed environment (www.columbus-concept.com). The Columbus foods include egg, milk, meat, oil, and bread, all rich in w-3 fatty acids, similar to wild foods, consumed about 160 years ago from now. Blood lipid composition does reflect one's health status: (a) circulating serum lipoproteins and their ratio provide information on their atherogenicity to blood vessels and (b) circulating plasma fatty acids, such as $\mathrm{w}-6 / \mathrm{w}-3$ fatty acid ratio, give indication on proinflammatory status of blood vessels; (a) and (b) are 
TABle 2: Estimated fatty acid consumption in the late Paleolithic period.

\begin{tabular}{lc}
\hline Sources & $\begin{array}{c}\text { Fatty acids (g/day) en } \\
35.65 / \text { day }\end{array}$ \\
\hline Plants & 4.28 \\
$\quad$ Linoleic acid & 11.40 \\
Alpha-linoleic acid & \\
Animal & 4.56 \\
$\quad$ Linoleic acids & 1.21 \\
Alpha-linolenic acid & \\
Total & 8.84 \\
Linoleic acid & 12.60 \\
Alpha linolenic acid & \\
Animal & 1.81 \\
Arachidonic acid (w-6) (AA) & 0.39 \\
Eicosapentaenoic acid (w-3) (EPA) & 0.12 \\
Docosatetraenoic acid (w-6) (DTA) & 0.42 \\
Docosapentaenoic acid (w-3) (DPA) & 0.27 \\
Docosahexaenoic acid (w-3) (DHA) & \\
Ratios of w-6/w-3 & 0.70 \\
Linoleic acid/alpha linolenic acid & 1.79 \\
AA+DTA/EPA+DPA+DHA & 0.79 \\
Total w-6/w-3 & \\
\hline
\end{tabular}

Modified from Eaton et al. in Simopoulos [14].

Table 3: Nutrient composition in the late Paleolithic and current recommendations.

\begin{tabular}{lcc}
\hline Nutrient & Late Paleolithic & $\begin{array}{c}\text { Current } \\
\text { recommendation }\end{array}$ \\
\hline Total dietary energy \% & 33 & 12 \\
$\quad$ Protein & 46 & 58 \\
$\quad$ Carbohydrate & 21 & 30 \\
$\quad$ Fat & -0 & moderate alcohol \\
Alcohol & 1.41 & 1.00 \\
P/S ratio & 520 & 300 \\
Cholesterol, mg & $100-150$ & $30-60$ \\
Fiber, g & 690 & $1100-3300$ \\
Sodium, mg & $1500-2000$ & $800-1600$ \\
Calcium, mg & 440 & 60 \\
Ascorbic acid, mg &
\end{tabular}

Modified from Eaton et al. in Simopoulos [14].

phenotype-related and depend on genetic, environmental, and developmental factors. As such, they appear as universal markers for holistic health. Blood cholesterol is central to this approach. Its 3D-representation shows how circulating lipoproteins affect blood vessels integrity upon their circulating throughout the body (Figure 1). Of major importance appear the essential dietary nutrients (essential amino acids, fatty acids, antioxidant vitamins, and minerals)
TABLe 4: Ethnic differences in fatty acid levels in thrombocytes phospholipids and percentage of all deaths from cardiovascular disease.

\begin{tabular}{lccc}
\hline & $\begin{array}{c}\text { Europe and } \\
\text { USA \% }\end{array}$ & Japan \% & $\begin{array}{l}\text { Greenland } \\
\text { Eskimos } \%\end{array}$ \\
\hline $\begin{array}{l}\text { Arachidonic acid } \\
(20: 4 \mathrm{w} 6)\end{array}$ & 26 & 21 & 8.3 \\
$\begin{array}{l}\text { Eicosapentaenoic } \\
\text { acid }(20: 5 \mathrm{w}-3)\end{array}$ & 0.5 & 1.6 & 8.0 \\
$\begin{array}{l}\text { Ratio of w-6/w-3 } \\
\text { Mortality from } \\
\text { cardiovascular } \\
\text { disease }\end{array}$ & 50 & 12 & 1 \\
$\begin{array}{l}\text { Modified from Weber by Simopoulos 2003 [14]. } \\
\text { n }\end{array}$ & 45 & 12 & 7 \\
\end{tabular}

TABle 5: Fatty acid ratio in the diets.

\begin{tabular}{lcc}
\hline Subjects & w-6/w-3 & \\
\hline Paleolithic & 0.79 & Estimated \\
Greece prior to 1960 & $1.00-2.00$ & Current 7.10 \\
Japan & 4.00 & Early 1-2 \\
India, rural & $5-6.1$ & Prior to 1960, 3-4 \\
India urban & $38-50$ & Prior to 1960, 5-10 \\
UK & 15.00 & Prior to 1960, 10.00 \\
Northern Europe & 15.00 & Prior to 1960, 10.00 \\
USA & 16.74 & Prior to 1950 7-8 \\
\hline
\end{tabular}

Modified from Simopoulos 2003 [3, 14].

and the functional component of the regimen (diet, sport, spiritualism, etc.). An example is given of an essential dietary nutrient and of a functional component of man's regimen that affect health in a predictive way derived from the $3 \mathrm{D}$ representation of blood cholesterol. Caption The Columbus Concept and its 3D representation of blood lipoprotein behaviors. "Bad" LDL-C, "good" HDLC, and "healthy" LDL-CC:HDL-CC ratios. CC = Columbus Concept. The Tsim Tsoum Concept is an extension of the Columbus concept which includes the simultaneous approach of controlling of Mind-brain-body connection by diet and lifestyle changes and by modulating mental load and circadian rhythm (Figure 2). The word Tsim Tsoum is derived from Hebreu and it is similar to ying yang in Chinese (http://www.tsimtsoum.net/editorials/tsimtsoum_editorial _2009-Kosice-14th-WCCN-and-5th-ICCD.pdf) sachs and group [16-18] used Dietary Approches to Stop Hypertension (DASH). For decreasing blood pressures, blood lipoproteins, and coronary risk. Similar dietary [19-24] interventions have been used by other workers for the last three decades to modulate blood pressure, obesity, diabetes, dyslipidemia and coronary risk in patients with high risk of CVD.These strategies appear to be similar to Columbus diet and lifestyle which may be protective, due to a favourable fatty acid ratio, antioxidants, and slowly absorbed nutrients in the diet. 
TABLE 6: Dietary guidelines and desirable level of risk factors for populations.

\begin{tabular}{|c|c|}
\hline Factors & Desirable Values \\
\hline Energy (k calories/day) & $1900-2300$ \\
\hline Total Carbohydrate (k calories/day) & 65.0 \\
\hline Complex Carbohydrate (k calories/day) & 55.0 \\
\hline Total Fat (k calories/day) & 21.0 \\
\hline Saturated Fatty Acids (k calories/day) & 7.0 \\
\hline Polyunsaturated Fatty Acids (k calories/day) & 7.0 \\
\hline Polyunsaturated/Saturated Fat Ratio & 1.0 \\
\hline$n-6 / n-3$ Fatty Acid Ratio & $1: 1$ \\
\hline Dietary Cholesterol (mg/day) & 100 \\
\hline $\begin{array}{l}\text { Whole Grains (wheat, rice, corn, and } \\
\text { legumes) (g/day) }\end{array}$ & $400-500$ \\
\hline Fruit, vegetables, and nuts (g/day) & $400-500$ \\
\hline Salt (g/day) & $<6.0$ \\
\hline Brisk Walking (km/day) & 9.0 \\
\hline Meditation/pranayam (minutes/day) & 30.0 \\
\hline \multicolumn{2}{|l|}{ Body Mass Index $\left(\mathrm{kg} / \mathrm{m}^{2}\right)$} \\
\hline Range & $19.0-23.0$ \\
\hline Average & 21.0 \\
\hline \multicolumn{2}{|l|}{ Waist-Hip Girth Ratio } \\
\hline Male & $<0.88$ \\
\hline Female & $<0.85$ \\
\hline $\begin{array}{l}\text { Serum Total Cholesterol }(\mathrm{mg} / \mathrm{dL}) \\
(4.42 \mathrm{mmol} / \mathrm{L})\end{array}$ & $<170$ \\
\hline $\begin{array}{l}\text { Mild Hypercholesterolemia }(\mathrm{mg} / \mathrm{dL}) \\
(4.42-5.20 \mathrm{mmol} / \mathrm{L})\end{array}$ & $170-200$ \\
\hline $\begin{array}{l}\text { Hypercholesterolemia }(\mathrm{mg} / \mathrm{dL}) \\
(>5.20 \mathrm{mmol} / \mathrm{L})\end{array}$ & $>200$ \\
\hline $\begin{array}{l}\text { Low Density Lipoprotein Cholesterol } \\
(\mathrm{mg} / \mathrm{dL})(2.32 \mathrm{mmol} / \mathrm{L})\end{array}$ & $<90$ \\
\hline $\begin{array}{l}\text { Borderline High }(\mathrm{mg} / \mathrm{dL})(2.32-2.84 \\
\mathrm{mmol} / \mathrm{L})\end{array}$ & $90-110$ \\
\hline High $(\mathrm{mg} / \mathrm{dL})(2.84 \mathrm{mmol} / \mathrm{L})$ & $>110$ \\
\hline Triglycerides $(\mathrm{mg} / \mathrm{dL})(1.7 \mathrm{mmol} / \mathrm{L})$ & $<150$ \\
\hline $\begin{array}{l}\text { High Density Lipoprotein Cholesterol } \\
(\mathrm{mg} / \mathrm{dL})(0.9 \mathrm{mmol} / \mathrm{L})\end{array}$ & $>40$ men, $>50$ women \\
\hline Blood Pressure (mmHg) & $<135 / 88$ \\
\hline $\begin{array}{l}\text { Drug therapy in view of high risk of diabetes } \\
\text { and CAD. }\end{array}$ & $\begin{array}{l}\text { Amblodipine, ACE-I, } \\
\text { receptor blockers and } \\
\text { new beta-blockers? Fish } \\
\text { oil, aspirin, and statins }\end{array}$ \\
\hline
\end{tabular}

\section{Development of Cardiovascular Diseases and Diabetes}

Overweight and central obesity, may cause clustering of risk factors which may be characterized with impaired glucose tolerance, with an adverse lipid profile and oxidative stress leading to hypertension and may be seen as early as in childhood and adolescence. These risk factors, which are indicators of metabolic syndrome and CVD, tend to be clustered more rapidly in children and adolescents with unhealthy lifestyles and diets such as those with excessive intakes of saturated fats, cholesterol, refined carbohydrates and salt and inadequate consumption of dietary fibre,

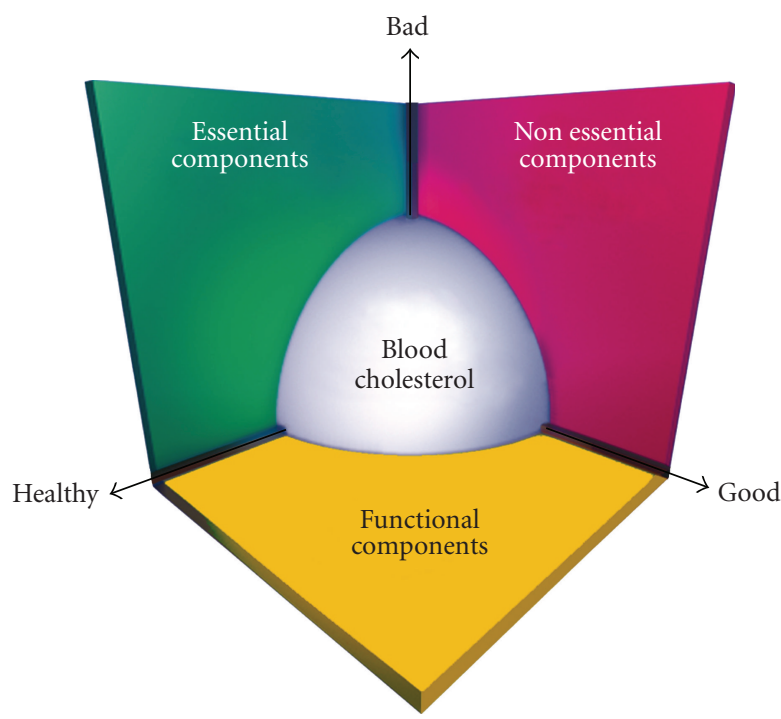

Figure 1: Blood cholesterol as a Marker for Holistic Health. The Columbus Concept (www.columbus-concept.com) deals with lifestyle's essential components to man's health. The Tsim Tsoum Concept (www.tsimtsoum.net) focuses on lifestyle's functional components to human health. These latter differ from the former components in that they do not contribute to the daily energy intake (DEI $= \pm 0$ ) on the one hand, and tend to elevate man to humanbeing on the other hand. They encompass those components that characterize the noninvasive interaction of man's body/mind with his environment through recognition of his evolutionary nature, that is, heritage and development.

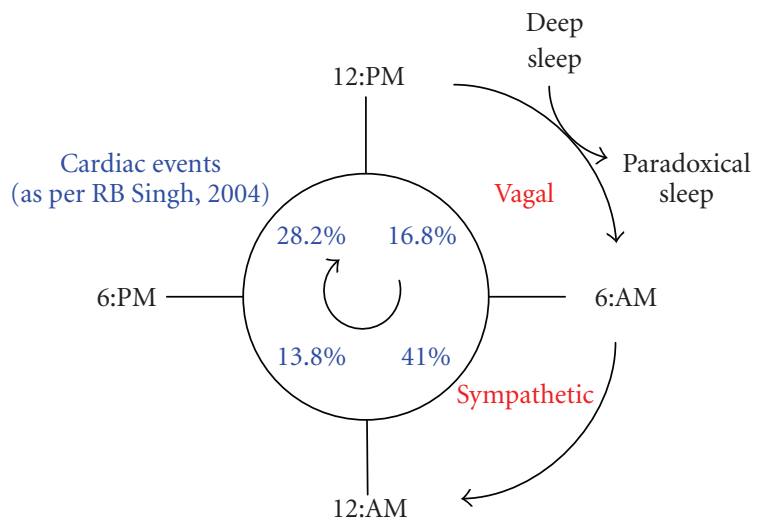

Figure 2: Circadian Rhythms of ACS, Columbus \& Tsim Tsoum Concepts. Tsim Tsoum \& Coloumbs around the clock.

antioxidants, vitamins, minerals, coenzyme Q10, and w-3 fatty acids. Low power mitochondria, due to coenzyme Q deficiency, may be associated with reduced aerobic capacity and predispose the metabolic syndrome and CVD [25-30]. Lack of physical activity and increase in television viewing are other factors which further increase the risk by decreasing basal metabolic rate (BMR) [1-3]. In older children and adolescents, habitual alcohol and tobacco use also contribute to high blood pressure and to the development of other risk factors in early adulthood which continue to act in later life 
course. Such clustering of risk factors which is characteristic of metabolic syndrome and CVD, represents an opportunity to address more than one risk factor at a time and may be due to clustering of health related behaviours [30]. Of the several characteristics of metabolic syndrome, at least 3 should be present for its diagnosis. Obesity in conjunction with type 2 diabetes, hypertension, coronary artery disease (CAD), and dyslipidemia are important features of the metabolic syndrome which is usually associated with hyperinsulinemia and insulin resistance $[25,26,31]$.

There is coexistence of nutritional deficiencies and appreciable overnutrition in the form of central obesity and overweight in both developed and developing countries [11-13, 15-37]. Cohort studies clearly showed that the gratifying gains in cardiovascular health occurred in developed countries, in association with an epidemic of CVD in the developing world [25-27, 31]. We have been in a position to learn, the mechanism of transition from poverty to economic development and emergence of cardiovascular disease (CVD) $[11,32]$. It seems that metabolic syndrome is an important pathway for development of CVD and type 2 diabetes. We proposed that "overweight comes first in conjunction with hyperinsulinemia, increased angiotensin activity, increased proinflammatory cytokines and central obesity followed by glucose intolerance, type 2 diabetes, hypertension, low high density lipoprotein cholesterol (HDL) and hypertriglyceridemia (Metabolic syndrome) [25-27]. This sequence is followed by CAD, gall stones and cancers and finally dental caries, gastrointestinal diseases and bone and joint diseases, during transition from poverty to affluence". As people become rich, they begin to increase their dietary fat, salt and sugar (proinflammatory foods) intake in the form of ready prepared foods, syrups, dairy products and flesh foods in place of grain based diet [27]. There is a greater use of automobiles, television viewing and decrease in sports, walking and dancing as recreation. These changes in the diet and lifestyle in conjunction with increased tobacco and alcohol intake, appear to be basic factors in the pathogenesis of noncommunicable diseases, including CVD $[3,31]$. The last few decades of the 20th century offered us an opportunity to initiate action to counter growing epidemics of CVD and type 2 diabetes, on both sides of the Atlantic [25-30, 38]. When people learned the methods of prevention, there was a decrease in CVD in the western world but obesity continued to increase, resulting into an increase in the metabolic syndrome in both developed and developing economies $[25,26,31]$. It is possible that these adverse diet and lifestyle factors damage the mitochondria of the cardiovascular system and ventromedial hypothalamus, leading to CVD and diabetes.

\section{Fatty Acids in the Diet and Development of CVD and Diabetes}

There has been an enormous increase in w- 6 fatty acid (about $30 \mathrm{~g} /$ day) in the diet due to the production of oils from vegetable seeds such as corn, sunflower, saiflower, soybean, and cotton. Increased intake of meat has resulted into greater intake of arachidonic acid $(0.2-1.0 \mathrm{mg} /$ day), whereas the consumption of alpha-linolenic acid (ALA) has decreased (about $0.55 \mathrm{~g} / \mathrm{day}$ ) and the amounts of eicosapentaenoic acid (EPA) and docosahexaenoic acid (DHA) are 48 and $72 \mathrm{mg} /$ day, respectively, [25-29, 31, 37]. A relative and absolute decrease in $\mathrm{w}-3$ fatty acids has led to an imbalance and increase in the ratio of $\mathrm{w}-6 / \mathrm{w}-3$ fatty acids to upto 50 in India and other developing countries, consuming vegetable seed oils (corn, soyabean, sunflower, and cotton) [27-30, 3840]. Saturated fatty acids (SFA) and trans fatty acids (TFA) elevate, PUFA decrease and MUFA have beneficial effects on total and low density lipoprotein cholesterol (LDL) as well as on HDL cholesterol. Omega-6 PUFA and TFA also decrease HDL cholesterol, and increase insulin resistance, free radical stress, and inflammation, which may enhance atherosclerosis [27-29]. Increased intake of total fat, TFA, SFA, and w6 fatty acids and refined carbohydrates, may cause insulin resistance resulting into metabolic syndrome [23, 24, 3137]. Decreased intake of MUFA, w-3 fatty acids, fiber, and phytochemicals may enhance the metabolic syndrome [1537].

\section{Cardiovascular Disease in Developing Countries}

Coronary risk factors in the developing world include low concentration of HDL cholesterol, hyper triglyceridemia, abdominal obesity, high prevalence of type 2 diabetes and $\mathrm{CAD}$, and hypertension, indicating presence of metabolic syndrome and CVD [38-41]. Sedentary lifestyle, increase in dietary fat, refined carbohydrate, and alcohol consumption are common behaviour patterns underlying above risk factors. Insulin resistance is nearly universal in all these conditions and South Asians are at the greatest risk of developing CAD and diabetes [30, 38-40]. These behaviour patterns result into hyper insulinemia but insulin resistance may differ and may not occur in all tissues of the body. Adipose tissue is not resistant to insulin in the early stages of whole-body insulin resistance, but muscle is resistant very early in the progression of metabolic syndrome X. Therefore, physical activity and yogasans, appear to be important in the prevention and treatment of insulin resistance. There is no scientific evidence to demonstrate that metabolic syndrome among South Asians is genetic in origin. It is possible that populations in developing countries, under scarcity, may have adapted to survive at low fat intake and physically demanding occupations, which made them more susceptible to dietary energy, sedentary behavior, and to established risk factors [42-50]. Abdominal obesity (central deposition of fat) in South Asians, appears to be universal in all the countries, wherever they are living, but whether the development of this type of obesity is genetic, dietary, caused by low physical activity, or a combination of these factors has not been established. Central obesity appears to be more prominent in the South Asian population than in the other Asian and Western populations. It is possible that transgenic mice overexpressing $11 \beta$ hydroxysteroid dehydrogenase type 1 (11 $\beta$ HSD-1) selectively in adipose tissue can develop abdominal obesity and exhibit insulin-resistant diabetes, hyperlipidemia, and hyperphagia despite hyperleptinemia 
[50]. It is not known whether adipose tissue from the abdomens of South Asians show increased 11ßHSD-1 activity. If this is true, peroxisome proliferator-activated receptor$\gamma$ ligands, which markedly reduce adipocyte $11 \beta \mathrm{HSD}-1$ activity in vitro and in vivo preferentially reduce abdominal fat, may be the drugs of choice in South Asians to reduce insulin resistance and obesity $[43,50]$. South Asians may be genetically programmed or due to maladaptation may overxpress $11 \beta \mathrm{HSD}-1$ in their adipose tissue, which may account for their higher risk of metabolic syndrome. It is possible, that treatment of central obesity with these agents, may be protective against metabolic syndrome, in South Asians [43, 50].

Singh et al. [43], in one cross-sectional survey, among 255 rural 311 urban elderly subjects, showed that mean blood pressures, body mass index, insulin levels, and the prevalence of hypertension were significantly greater among urban compared to rural population. Total fat intake was significantly greater among urban and hypertensive subjects compared to rural normotensive and hypertensive subjects, respectively. A recent study [46], among 54 patients of acute myocardial infarction (AMI), showed that the intake of large meals and large breakfast $>1000$ cal especially rich in TFA was significantly associated with AMI compared to control subjects. Those consuming large meals, showed significantly greater levels of tumour necrosis factor-alpha (TNF- $\alpha$ ) and interleukin-6 (IL-6) compared to subjects taking small breakfast. In another study [34], among 202 patients, large meals was a trigger for development of AMI among half of the patients. TNF- $\alpha$ and IL-6, incidence of known hypertension, and type- 2 diabetes were significantly greater among AMI patients compared to healthy subjects. These proinflammatory markers are risk factors of AMI and metabolic syndrome [42]. In one cross-sectional survey [47], among 3257 women, aged 25-64 years, social class 1-3 were consuming significantly greater amount of total visible fat, including TFA, clarified butter (Indian ghee), and vegetable oils, compared to lower social classes 4 and 5. Mean body mass index (BMI), over weight (BMI $>25 \mathrm{Kg} / \mathrm{M} 2)$, and central obesity (Waist-hip ratio $>85$ ) were significantly greater among higher social classes than lower social classes.

Higher social classes 1-3 are known to have greater prevalence of $\mathrm{CAD}$, type 2 diabetes and hypertension, indicating metabolic syndrome in Indians. It is possible that lower intake of w-3 fatty acids and MUFA, as well as increased consumption of w- 6 fatty acids, SFA, and TFA may be responsible for central obesity and metabolic syndrome among these patients [40, 47-49]. In another study [50], among $850 \mathrm{men}$, aged 25-64 years, subjects were divided into high fat, over-fat, normal-fat, and under-fat based on criteria of body fat analysis by bioelectrical impedance. The prevalence of CAD, type 2 diabetes, and hypertension, as well as low HDL cholesterol, BMI, and WHR were significantly associated with high body fat percentage.

\section{Interactions of Gene and Environment}

Dietary factors, physical activity, mental stress, and environmental toxicants can influence gene expression and have shaped the genome over several million years of human evolution $[14,44,49]$ which has given an opportunity for health, as well as susceptibility to diseases, through genes, while environmental factors determine which susceptible individuals will develop metabolic syndrome. Rapid changes in diet and lifestyle due to socioeconomic changes provide added stress causing exposure of underlying genetic predisposition to chronic diseases such as type 2 diabetes, obesity, hypertension, CAD, and atherosclerosis. Several studies are continuing on the role of nutrients in gene expression [49]. It is not clear how n-3 fatty acids suppress or decrease the mRNA of interleukin, which is elevated in atherosclerosis, arthritis and other autoimmune diseases, whereas $n-6$ fatty acids have no such effects [49]. Metabolic syndrome appears to be polygenic in nature and rapidly escalating rates suggest the importance of environmental change, rather than changes in genetic susceptibility.

It has been proposed [42-50] that genetic and other factors, including oxidative stress; superoxide anion $\left(\mathrm{O}_{2}\right)$ and hydrogen peroxide $\left(\mathrm{H}_{2} \mathrm{O}_{2}\right)$, endothelial nitric oxide (eNO), lipid peroxides, antioxidants, endothelin, angiotensin converting enzyme (ACE) activity, angiotensin-II, transforming growth factor- $\beta$ (TGF- $\beta$ ), insulin, homocysteine, asymmetrical dimethyl arginine, proinflammatory cytokines: interleukin-6 (IL-6), tumor necrosis factor- $\alpha$ (TNF- $\alpha$ ), Creactive protein (hs-CRP), long-chain polyunsaturated fatty acids (LCPUFAs), and activity of $\mathrm{NAD}(\mathrm{P}) \mathrm{H}$ oxidase have a role in human essential hypertension. There is a close interaction between endogenous molecules: (endothelial nitric oxide) eNO, endothelin, cytokines, and nutrients: folic acid, coenzyme Q10, L-carnitine, L-arginine, tetrahydrobiopterin $\left(\mathrm{H}_{4} \mathrm{~B}\right)$, vitamin $\mathrm{B} 6$, vitamin $\mathrm{B} 12$, vitamin $\mathrm{C}$, and LCPUFAs. Statins can mediate some of their actions through (LCPUFAs), whereas these fatty acids (especially $\omega$-3 fatty acids) suppress cyclooxygenase activity and the synthesis of proinflammatory cytokines, and activate parasympathetic nervous system. This activity can reduce the risk of major vascular events. LCPUFAs such as EPA, DHA from precursors to lipoxins and resolvins may have antiinflammatory actions. Low-grade systemic inflammation seen in hypertension seems to have its origins in the perinatal period and availability of adequate amounts of LCPUFAs during the critical periods of brain growth prevents the development of hypertension [14]. This indicates that preventive strategies aimed at decreasing the incidence of hypertension and its associated conditions such as atherosclerosis, type 2 diabetes, $\mathrm{CAD}$, and cardiac failure in adulthood need to be prevented during the perinatal period for primordial prevention of metabolic syndrome.

\section{Dietary Factors and Cardiovascular Disease}

Experimental studies indicate that type and amount of dietary fatty acids may cause insulin resistance and metabolic syndrome [51]. MUFA or w-3 fatty acids appear to have beneficial effects on insulin action, whereas w- 6 fatty acids, saturated fats and diets with high total-fat content, appear to decrease insulin sensitivity in animal studies $[30,38,39]$. It is hypothesized that dietary fats affect the phospholipid 
composition of cell membranes in skeletal muscle and other tissues. Several clinical studies showed a decrease in insulin sensitivity with high fat diets [52, 53]. A few studies diminish the strength of their conclusions, including large difference in diets, the nonrandomized assignment of diets, and lack of standardized methods to measure insulin sensitivity. A few studies using more standard measures reported a relationship between fat content and insulin sensitivity [54]. One reason may be the relatively short duration of intervention in many of these studies. A recent multicenter, 3-month investigation found that a diet high in saturated fat (18\% of energy) decreased insulin sensitivity more than a diet high in monounsaturated fat $(21 \%$ of energy) among 162 healthy men and women [55]. Many cross-sectional epidemiologic studies also demonstrated positive association between intake of saturated fat and hyperinsulinemia, after adjustment for measure of body fat $[56,57]$, but at least one large, well-designed study showed no association [58]. Prospective studies including the Nurses' Health Study [59] suggest the role of specific types of fat in the development of type 2 diabetes mellitus. In the Nurses' Health Study, investigators reported an inverse association between development of diabetes and intake of vegetable fat and polyunsaturated fat, a positive association for trans-fatty acids, but no association for total fat in the diet. In a more recent study [60], among 15 obese, hyper insulinemic subjects, a hypoenergetic, MUFA-rich diet containing 35\% carbohydrate, $45 \%$ fat, and 20\% protein was compared with a diet containing; $60 \%$ carbohydrate, $20 \%$ fat, and $20 \%$ protein. After 4 weeks, fasting insulin levels, insulin to glucose ratio, Homeostatic Model, and Assessment Index decreased to normal ranges and were significantly lower in high MUFA group as compared with the control group. However, insulin sensitivity score increased significantly, waist circumference showed significant decline, in the high MUFA group compared to high carbohydrate group, indicating improved insulin sensitivity and decreased central obesity, respectively, with MUFA-rich diet. In a crosssectional population study [61], Folsom et al. reported among 4000 healthy subjects that fasting insulin levels were positively associated with the percentage of saturated fat in plasma, and inversely associated with percentage of MUFA. Lovejoy et al. [62] observed that certain class of fatty acids such as w-6, saturated and TFA have more deleterious effects on insulin action than others, and increase the risk of type 2 diabetes mellitus and therefore metabolic syndrome. Low and coworkers [63] found that a high MUFA diet induced improvement in the control of type 2 diabetes as compared to high carbohydrate diet. Similar results were noted by other workers $[60,64]$. In one study, MUFA-rich diet also reduced the total cholesterol to HDL-cholesterol ratio, compared to high carbohydrate diet [65].

A greater reduction in triglyceride levels was observed in the high MUFA group than in the high carbohydrate group $[65,66]$. These results were observed in earlier studies [67] showing that dietary fatty acid composition affects the fatty acid composition of VLDL-triglyceride and alterations in composition of VLDL and in the enzymes involved in its catabolism are two mechanisms observed in the hypotriglyceridemic effect of high MUFA diets [68]. Oleic acid has also been found to cause a reduction in triglyceride levels, possibly through increasing the removal of triacylglycerol [69]. Moreover, olive oil has been found to promote gastrointestinal secretions and stimulate stomach emptying, thereby increasing the rate of supply of fatty acids to the enterocytes [70], thus accelerating the rate of digestion and absorption and faster rate of entry of chylomicrons into the circulation. This implies that the long-term use of olive oil may cause up-regulation of the enterocytes' ability to process dietary triacylglycerol and synthesize chylomicrons [71]. However, high carbohydrate diets are known for their hypertriglyceridemic effects and glucose intolerance [72] which appear to be due to downregulation of muscle lipoprotein lipase (LPL) activity [73]. These adverse effects of such diets can enhance diabetes and cardiovascular disease or metabolic syndrome [74-78]. The Columbus concept of diet; including fruits, vegetables, whole grains, nuts, w-3 fatty acid rich egg, and meats, and Columbus oil (olive oil+lin seed oil) in conjunction with physical activity addresses both diet and lifestyle, may be useful in the prevention of metabolic syndrome as well as its components [14, 79-81].

\section{Diet and Inflammation and Endothelial Dysfunction}

Vascular indexes should be independently considered as risk factors of atherothrombosis, because of antiinflammatory effects of statins, hormone replacement therapy (HRT) and postprandial endothelial dysfunction, in relation to inflammation [27-29] impaired vascular biology, physiology, and biochemistry resulting into inflammation and endothelial dysfunction may be independently atherothrombotic [27, $82]$.

There is evidence that abnormalities of the postprandial state are important contributing factors to the development of atherosclerosis $[45,46,82]$. Recent studies indicate that changes in LDL cholesterol and C-reactive protein independently correlated with coronary atherosclerosis progression and coronary events $[83,84]$. However, on treatment, Creactive protein was as predictive of subsequent coronary events as was LDL cholesterol. HRT increases HDL cholesterol, and endothelial function, as well as inflammation and coagulation which are atherogenic, hence HRD has been discarded.

Clinical data indicate that postprandial hypertriglyceridaemia is a risk factor for cardiovascular disease in nondiabetic subjects and may be a predictor of carotid intimamedia thickness in type 2 diabetic patients [85]. Meal absorption is a complex phenomenon, and postprandial hyperlipidaemia and hyperglycaemia are simultaneously present in the postabsorptive phase, particularly in diabetic patients or in subjects with impaired glucose tolerance [9, $82,85,86]$. Both postprandial hyperglycaemia and hypertriglyceridaemia may cause endothelial dyfunction, which is considered an early marker of atherosclerosis [27]. Effect of different isocaloric meals on endothelial function in both normal subjects and type 2 diabetic patients, may be that the level of triglycerides after a high-fat (saturated) meal may 
be associated with endothelial dysfunction, with maximal impairment occurring at the time of the simultaneous presence of postprandial hyperglycaemia and hypertriglyceridaemia [27]. The effect of liquid meals rich in carbohydrates or saturated fats may be similar. It is possible that endothelial dysfunction induced by a high-fat meal in type 2 diabetic patients or associated with fasting hypertriglyceridaemia in young men could be associated with increased plasma concentrations of asymmetric dimethylarginine, an endogenous nitric oxide synthase inhibitor, suggested as a novel cardiovascular risk factor [87].

A mild prooxidative state accompanies meal ingestion, which results in raised circulating biomarkers of inflammation, adhesion, and endothelial dysfunction, all of which are factors in the development of cardiovascular disease [88]. The effect of hyperglicaemia, hypertriglyceridaemia, and raised free fatty acids (FFA) levels both fasting and postprandial, on endothelial function may be mediated through the generation of an oxidative stress [27, 88]. The process is supposed to involve increased superoxide generation, which in turn inactivates nitric oxide. Superoxide and nitric oxide combine to produce peroxynitrite, a potent and long-lived oxidant, that is, cytotoxic, initiates lipid peroxidation and nitrates amino acids such as tyrosine which affects many signal transduction pathways. The production of the peroxynitrite anion can be indirectly inferred by the presence of nitrotyrosine (NT). An increase in plasma NT levels has been reported in association with postprandial hyperglycaemia or hypertrigly-cidaemia, with a cumulative effect occurring in the presence of both conditions [27-29]. It seems therefore that oxidative stress is a mediator of the effect of raised substrate concentration in the postprandial phase $[89,90]$. It is clear that what happens during the absorption phase may be of considerable importance, because it occurs several times every day and human beings now spend an increasingly greater part of their lives in the postprandial phase without periods of fasting. These biological markers after a high-fat meal, also rich in refined carbohydrates, appear to be basic underlying mechanism for insulin resistance and metabolic syndrome leading to CVD [91].

\section{Proinflammatory Macronutrients}

Proinflammatory macronutrients such as w- 6 fatty acids, TFA and SFA as well as refined carbohydrates intake may produce oxidative stress and proinflammatory substances [27] (Figures 1 and 2). Glucose ingestion in normal subjects is associated with increased superoxide generation in leukocytes and mononuclear cells, as well as with raised amount and activity of nuclear factor- $\kappa \mathrm{B}$ (NF- $\kappa \mathrm{B})$, a transcriptional factor regulating the activity of at least 125 genes, most of which are proinflammatory [91]. Increased consumption of refined carbohydrates also causes an increase in two other proinflammatory transcription factor, activating protein-1 (AP-1), and Egr-1, the first regulating the transcription of matrix metalloproteinases and the second modulating the transcription of tissue factor and plasminogen activator inhibitor-1 [27, 91]. A mixed meal from a fast-food chain has also been shown to induce activation of NF- $\kappa \mathrm{B}$ associated with the generation of reactive oxygen species (ROS) by mononuclear cells. Superoxide anion appear to be an activator of at least two major proinflammatory transcription factor, NF- $\kappa \mathrm{B}$ and AP-1. These observations are consistent with previous findings, demonstrating that after oral or intravenous glucose challenges, in both normal subjects and patients with type 2 diabetes mellitus, there is an increased generation of ROS and raised circulating levels of proinflammatory cytokines, such as TNF- $\alpha$, IL-6, and IL18 [27, 92-94]. In apparently healthy subjects, a single highfat meal produces endothelial activation, as evidenced by increased concentrations of the adhesion molecules VCAM1 (vascular cell adhesion molecule-1) and ICAM-1 (intercellular adhesion molecule-1), in association with raised plasma concentrations of IL-6 and TNF- $\alpha$ [27]. A high-fat meal [94] may increase the circulating levels of IL-18, a proinflammatory cytokine supposed to be involved in plaque destabilization associated with the simultaneous decrease of circulating adiponectin, an adipocyte-derived protein with insulin sensitizing, antiinflammatory, and antiatherogenic properties [95].

\section{Diet, and Insulin Resistance}

Biological dysfunctions, found in diabetes, obesity, and the metabolic syndrome include, among others, increases in the circulating levels of metabolites, such as FFA and triglycerides, and cytokines such as TNF- $\alpha$ and IL-6. Administration of a marcronutrient, causes a shift towards oxidative stress and inflammation, which in turn may reduce insulin sensitivity. FFA as well as proinflammatory markers have been shown to predict type 2 diabetes independent of known risk factor $[96,97]$. Both FFA and TNF- $\alpha$ have also been shown to activate inhibitor $\mathrm{K}$ kinase $\beta$ (IKK- $\beta$ ) in adipocytes and hepatocytes, which can then increase the serine phosphorylation of insulin receptor substrate1 (IRS1 ), with subsequent reduction in insulin-dependent tyrosine phosphorylation of IRS-1, and ultimately glucose transport [98]. IKK $\beta$ is a serine kinase that controls the activation of NK- $\kappa \mathrm{B}$, a transcription factor associated with inflammation. IRS-1 may be directly phosphorylated by IKK- $\beta$ at serine residues, respresenting a novel class of substrates for IKK $\beta$ [99]. In one recent study [100] in which hepatic expression of the lkappaBalpha superrepressor, which reduces IKK $\beta$ activity, reversed the phenotype of wild-type mice fed diet. It is possible that lipid accumulation in the liver leads to subacute hepatic "inflammation" through NK- $\kappa$ B activation and downstream cytokine production resulting into insulin resistance both locally in liver as well as systemically. Circulation of IL-6 in plasma is at high concentrations and is associated with insulin resistance in men and in obese or hyperandrogenic women [27]. Circulating IL-6 levels and insulin sensitivity relationships seem to occur in parallel to increases in plasma FFA. In contrast to IL6 and TNF- $\alpha$, adiponectin mRNA is reduced in adipose tissue from patients with type 2 diabetes [95]. It seems that low adiponectin production contributes to insulin resistance and there is evidence that adiponectin decreases circulating FFA levels by increasing fatty acid oxidation by 
skeletal muscle [101]. The endogenous proinflammatory potential may be greater, in the postprandial phase, due to imbalance in pro and antiinflammatory cytokines, particularly following the ingestion of rapidly absorbed foods. Modification of circulating FFA levels may mediate a part of this effect and blunting of antiinflammatory actions of insulin might also play a role. Insulin causes a suppression of $\mathrm{NK}-\kappa \mathrm{B}$, at physiologically relevant concentrations, thus reducing the production of some of its transcripts, namely IL-6 and TNF- $\alpha$ [27]. This benefit of insulin, has been related to its ability to induce the release of nitric oxide and to enhance the expression of constitutive nitric oxide synthase.

\section{Dietary Approaches to Stop Endothelial Damage}

The vascular effects of high sugar and high fat meals have greatly increased our understanding about the role of diet on atherothrombosis [28]. There is increased flux of nutrients in the postprandial state which is associated with an increase in circulating levels of proinflammatory cytokines, recruitment of netrophils and oxidative stress. The generation of reactive oxygen species (ROS) may be a common ground for all these findings and may help understanding current dietetic recommendations of the International College of Cardiology, emphasizing increased consumption of fruits, vegetables, (400 g/day), nuts ( $50 \mathrm{~g} /$ day $)$, and grains ( $400 \mathrm{~g} /$ day $)$, spices, and MUFA+w-3 fatty acids rich oils (30-50 g/day). Fruits, vegetables, nuts and spices are rich in natural antioxidants, phytochemicals, and fibre that help fighting the oxidant wave of meals. Decreasing the intake of $w-6$, trans- and saturated fatty acids and increasing the consumption of omega-3 fatty acids (lin, mustered, and canola oil) and MUFA (olive oil) are also considered important strategies to reduce $\mathrm{CAD}$ and metabolic syndrome $[25,26,31]$.There is evidence that these two strategies are also associated with a reduced inflammatory status. In the Nurses Health Study, levels of C-reactive protein and markers of endothelial dysfunction were $73 \%$ higher in the highest quintile of transfatty acids intake, compared with the lowest quintile [102] and low-cholesterol/low-saturated fat diets are associated with mitigation of low-grade systemic inflammation which correlated with reduction of plasma C-reactive protein levels [103]. Cross-sectional study from the Nurses' Health Study I cohort demonstrated lower concentrations of many markers of inflammation and endothelial activation, including Creactive protein, IL-6, and E-selectin, among those in the highest quintile of omega-3 fatty acids, when compared with the lowest quintile [104]. Since a high intake of omega- 6 fatty acids may reduce the known beneficial effects of omega-3 fatty acids on CAD risk [49]; a combination of both types of fatty acids in a ratio of $1: 1$ as advised by Columbus concept Institute, which may be associated with the lowest level of inflammation [105].

However, it seems that $\mathrm{w}-6 / \mathrm{w}-3$ ratio in the diet should be $<5.0$ to have optimal benefit of these fatty acids in the prevention of CVD, type 2 diabetes, and metabolic syndrome.
Since free radical stress is supposed to play a key role in the development of atherosclerosis, antioxidant-vitamin supplementation has been suggested for the treatment and prevention of chronic diseases, including CAD [44]. The encouraging results of short-term trials in participants with coronary atherosclerosis were not confirmed in large-size intervention trials. It seems that it is wrong to focus on a single element of the diet; guideline from some professional or governmental panels recommend to consume vitamins and minerals from food sources, rather than from supplements $[44,105]$. A shift towards energy dense, refined, ready prepared foods with high glycemic index (refined starches and sugar) and unhealthy lipids (TFA, SF, and w-6 rich oils) poor in phytochemicals and fibre have been adopted by increased number of people and populations in the western world and in the urban populations of middle income countries in the last few decades [26, 42-48]. These changes in diet can cause an inctivation of innate immune system, by excessive production of proinflammatory cytokines and reduced production of antiinflammatory cytokines, which may result into generation of inflammatory milieu, causing insulin resistance, and endothelial dysfunction. These changes in diet in conjunction with inadequate physical activity appear to be responsible for the development of positive energy balance, weight gain, and central obesity, which is widely acknowledged as an endocrine organ, secreting an increasing number of mediators, including proinflammatory cytokines [106]. Central obesity is a key promoter of low grade systemic inflammatory state [85, 86 ] and is characterized by the most severe metabolic abnormalities [28]. It seems that subjects with abdominal adiposity are particularly prone to the proinflammatory effects of unhealthy diets. The changes in dietary patterns that occurred in recent years are characterised with the intake of large amount of foods that seem faster in preparations and producing health damage. One prospective CARDIA (Coronary artery risk development in young adults) study indicate that frequent fast food intake causes weight gain and risk of insulin resistance, over 15 years [107].

The Quebec Family Study has shown that a decrease in the consumption of fat-foods or an increase in consumption of whole grains and fruits predicted a lower increase in body weight and adiposity indicators, over a 6-year followup [108]. However, no specific dietary recommendations have been advocated by health agencies for the treatment of insulin resistance or the metabolic syndrome [44, 80, 81]. Given that the metabolic syndrome is an identifiable and potentially modifiable risk state for both type 2 diabetes and cardiovascular disease, adopting a dietary pattern as that used by other workers may reduce the potential risk of these diseases [44, 109-113]. In one study, Knoops et al. [114], (Colleagues from the Netherlands, France, Spain and Italy) have demonstrated that in European men and women aged 70-90, adherence to a Mediterranean-style diet, which represents a solid example of a healthy dietary pattern, moderate alcohol consumption, nonsmoking status, and physical activity was associated with a lower rate of all-cause mortality. This combination of healthy diet and lifestyle, was associated with a mortality rate of about one-third that 
of those with none or only one of these protective factors. Another larger study, involving about 22000 adults, showed an inverse correlation between a greater adherence to a Mediterranean-style diet and death [115]. Approximately a $2 / 9$ increment in the Mediterranean diet score was associated with a $25 \%$ reduction in total mortality and a $33 \%$ reduction in CAD mortality.

\section{Intervention Trials}

Intervention trials, using the whole diet approach so far produced are also in line with this epidemiological evidence. In the Lyon Diet Heart Study [116], 605 patients who had a myocardial infarction were randomly assigned to a "Mediterranean-style" diet or a control diet resempling the American Heart Association Step I diet. The Mediterranean diet model supplied $30 \%$ of energy from fats and $<10 \%$ of energy from saturated fatty acids, whereas the intake of $18: 3(n-3)(\alpha$-linolenic acid) provided $>0.6 \%$ of energy. After a mean follow-up of 27 months, the risk of new acute myocardial infarction and episodes of unstable angina was reduced by $\sim 70 \%$ by the Mediterranean diet. Moreover, total mortality was also reduced by $70 \%$. Singh et al. [109] tested an "Indo-Mediterranean diet" in 1000 patients in India, with existing coronary disease or at high risk for coronary disease. When compared with the control diet, the intervention diet characterized by increased intake of mustard or soyabean oil, nuts (walnuts, almonds), vegetables, fruits and whole grains-reduced the rate of fatal myocardial infarction by one-third and the rate of sudden death from cardiac causes by two-thirds. Esposito et al. [110], randomized 180 patients ( 99 men, 81 women) with the metabolic syndrome to a Mediterranean style diet, characterized with whole grains, vegetables, fruits, nuts, and olive oil versus a cardiac-prudent diet with fat intake $<30 \%$. After a follow up of 2 years, subjects in the intervention diet showed greater weight loss, had lower C-reactive protein and proinflammatory cytokine levels, had less insulin resistance, as well as lower total cholesterol and triglycerides and higher HDL cholesterol. The prevalence of metabolic syndrome was reduced to one half. The Japan Public Health Centre-based study [111] showed that eating more w-3 fatty acids by increased intake of fish was associated with significant reduction in cardiovascular disease and cardiac mortality.

\section{The Indian Experiments of Infarct Survival}

Acute myocardial infarction(AMI) is associated with hyperglycemia, hypertrigly- ceridemia, hyperinsulinemia, increased FFA, free radical stress, IL-6, TNF-alpha, and deficiency of antioxidant vitamins and w-3 fatty acids, which appear to be responsible for complications and deaths among these patients [27, 112, 113, 117-127]. Therefore, AMI or acute coronary syndrome (ACS) appears to be the best model to examine the effects of any intervention on various biochemical markers and associated factors during AMI. Recent studies [28-30], indicate that eating high-fat, refind carbohydrate-rich fast foods (western diet), can produce a similar proinflammatory state in our body, resulting into endothelial dysfunction, which may have adverse effects in patients with AMI. It is therefore logical to avoid western diet in patients with ACS, and administer diet which is beneficial to vascular endothelium and myocardium. There is limited evidence regarding the role of dietary intervention in patients with AMI $[112,113,117,118]$. The aim of the Indian experiment was to determine the effects of a diet rich in w-3 fatty acids, vitamins, minerals and antioxidants (fruits, vegetables, legumes, walnuts, almonds, fish, mustoard, and soyabean oils) and low in refined carbohydrates, in patients with (AMI) [113, 117-119].

All patients with a diagnosis of ACS were assigned to an intervention diet $(n=204)$ or a control diet $(n=202)$ within 48 hours of the onset of the symptoms of AMI. The intervention group was advised to consume $600 \mathrm{~g} /$ day of fruits, vegetables, legumes, and almonds, and walnuts, in a soup or semisolid form. Tomato soup, skimmed milk, and curd (yogurt) were commonly used to mix crushed almonds and walnuts and other foods, which were grilled with mustered oil. The control group was advised a low-fat diet consistent with National Cholesterol Education Program. Clinical characteristics, time elapsed from symptom onset to the index infarction, site of infarction, drug therapy, and final diagnosis were comparable between the two groups. Intake of foods and selected nutrients was assessed during the 1 week and after 1 year. After 1 week, plasma lipid peroxides, vitamin $\mathrm{C}$, and lactate dehydrogenase levels were determined. Compared with the control groups, patients allocated to the dietary intervention consumed significantly greater amounts of fruit, vegetables, pulses, almonds, walnuts, oils, and fish both during the first trial week [113] and 1 year after AMI [118]. The consumption of $n-3$ fatty acids was also significantly greater in the intervention group than in the control group $\left(1.8 \pm 0.66\right.$ versus $0.65 \pm 0.4 \mathrm{~g} \mathrm{day}^{-1}, P<$ .01 , Table 2 ). The consumption of proinflammatory foods, such as butter and clarified butter, refined starches and sugar were significantly greater in the control group than in the intervention group (Table 2). Plasma lipid peroxide level decreased significantly in the intervention group compared with the control group, indicating a decrease in oxidative stress which is protective against proinflammatory IL-6 and TNF-alpha as well as endothelial disfunction, although these data were not measured in our study. Lactate dehydrogenase (LDH) level increased less in the intervention group than in the control group, indicating that myocardial damage was prevented by the cardioprotective diet (Table 3 ). The increased intake of $n-3$ fatty acids from mustard and soy bean oil associated with the Mediterranean diet might be responsible for the significant reduction in the cardiac enzyme LDH and lipid peroxides in the intervention compared with the control group. Total cardiac events, including fatal and nonfatal myocardial infarctions and sudden cardiac deaths, were significantly lower in the intervention group compared with the control group, both after 6 weeks [117] as well as after one year (Table 4) [118]. These Beneficial effects may be due to protection of mitochondria from damageing effects of free radicals. 
The effects of 1 year of treatment with fish oil (122 patients, eicosapentaenoic acid, EPA $1.08 \mathrm{~g} \mathrm{day}^{-1}$ ) mustard oil (120 patients, alpha-linolenic acid $2.9 \mathrm{~g} \mathrm{day}^{-1}$ ), and no treatment (118 patients, placebo group) on the outcome of patients with suspected AMI were compared in a randomized, placebo-controlled trial) [120]. Treatments were administratered within, on average $18 \mathrm{~h}$ of onset of symptoms. Clinical characteristics, extent of cardiac damage and rise of cardiac enzymes and lipid peroxides were comparable among the three groups at study entry. After randomization, angina pectoris $(18.0 \%$ and $21.6 \%$ versus $42.3 \%$ ), arrhythmias (13.1\% and $13.3 \%$ versus $28.7 \%)$ and poor left ventricular function $(22.8 \%$ and $26.6 \%$ versus $47.4 \%$ ) were significantly lower in the fish oil and mustard oil treatment groups compared with the placebo group. Sudden cardiac deaths (1.6\% and $1.6 \%$ versus $6.6 \%)$, total cardiac deaths (11.4\% and $13.3 \%$ versus $22.0 \%)$ non-fatal infarctions ( $13.0 \%$ and $15.0 \%$ versus $25.4 \%$ ), and total cardiac events (24.5\% and $28.2 \%$ versus $47.4 \%$ ) were also significantly lower in the two intervention groups. A modest improvement in dyslipidaemia and a decrease in oxidative damage were observed in the fish oil and mustard oil groups but not in the placebo group. On the third and the fifth day after AMI, serum glutamic oxalotransaminase (SGOT) and $\mathrm{LDH}$ cardiac enzymes showed greater decline in the fish oil and mustard oil groups compared with the placebo group. These intervention trials indicate that further studies should be conducted with Columbus diet and Columbus oil (olive oil+lin seed oil) in patients with AMI, to demonstrate, cytokine and endothelial function mediated mechanisms, in the pathophysiology of complications and deaths, among these patients.

There is no precise and proven guideline for dietary advice, in patients with AMI, which may be protective against recurrent cardiac events. A Columbus soup (tomatoes, grapes, vegetables, walnuts, almonds, lin seed, and olive oil) or yogurt containing, walnuts, almonds, raisins, could be prepared for ready use, for nonpharmacological intervention, among patients of AMI. Such recepies have been commonly used by us in our studies and clinical practice $[113,117-123]$. These strategies can influence receptors, enzymes and nitric oxide (NO) secretion via increased intake of w-3 fatty acids $[124,125]$ which are protective. These methods are similar to dietary approaches proposed in the the DASH diet used in earlier studies [16-18] in patients with multiple risk factors of CAD, indicating metabolic syndrome. The effects of diet on dyslipedimia and glucose were much better when these dietary interventions were combined with exercise $[58,59]$.

\section{Recommendations}

It is clear that high doses of EPA and DHA ( 3 to $4 \mathrm{~g}$ /day) have been shown to increase systemic arterial compliance, indicating that marine omega-3 PUFAs improve endothelial function [27, 126-129]. Therefore, a diet containing fish or fish oil supplements or columbus foods (eggs, chicken, and oils) rich in w-3 fatty acids [130], may be advised to provide protection against western diet-induced inflammation. Studies with ALA have been conflicting, with some positive and some negative studies. In a controlled trial [32], Columbus eggs showed beneficial effects on blood lipoproteins. Additionally, the omega-3 PUFAs exhibit an antiinflammatory effect. EPA and DHA reduced tumor necrosis factor, interleukin-6, vascular cellular adhesion molecule-1, and E-selectin at relatively low doses ranging from 0.3 to $1 \mathrm{~g} /$ day. Although fewer studies have been performed, the results have been mixed with respect to the effect of ALA on inflammatory markers such as C-reactive protein, vascular cellular adhesion molecule-1, E-selectin, and interleukin-6. The mechanistic studies with EPA and DHA have pointed to an antiarrhythmic effect, and data with ALA are less conclusive. Studies attempting to attribute other antiatherogenic properties to EPA, DHA, and ALA have not been consistent, and many of these studies have demonstrated effects at doses much higher than those used in clinical end point trials. As a result of the previously mentioned omega-3 PUFA trials and recent epidemiologic evidence, the American Heart Association has published guidelines for the consumption of fish and fish oil, indicating that patients with CAD should try to consume a combination of EPA and DHA totaling $1 \mathrm{~g}$ /day. Many patients, however; do not enjoy eating fish or have concerns about pollutants. Rich sources of ALA, including canola, lin and flax seed meal, and walnuts, can be easily incorporated into the western diets.

Columbus oil containing olive oil+lin seed oil could be the best combination along with western diet, for prevention of metabolic syndrome. If clinical trials demonstrate that ALA is as effective as EPA and DHA in reducing cardiovascular events, the public health implications could be significant. The evidence supports a role for fish oil (EPA, DHA) or fish in secondary prevention, because the clinical trials have demonstrated a reduction in total mortality, CHD death, and sudden death. The evidence from these trials has indicated that EPA plus DHA supplementation in the range of 0.5 to $1.8 \mathrm{~g}$ /day provides significant benefit. More research is needed to determine whether the benefits of fish oil or fish extend to the world population in secondary and primary prevention.

The data on the plant-based n-3 PUFA, ALA, is very promising. However, the existing studies were small, and a large randomized controlled trial is needed before recommendations can be definitely made for CHD prevention. The data for ALA indicate, possible reductions in sudden death and nonfatal myocardial infarction, suggesting other potential cardioprotective mechanisms other than a predominately antiarrhythmic role. An urgent need exists to perform more clinical trials with ALA because the results of such trials could have significant public health implications. Recommendations are given in Table 6.

Diet and lifestyle intervention can reduce the risk for conversion of IFG/IGT to type 2 diabetes. Clinical studies, indicate that metformin or thiazolidinediones also reduce risk for type 2 diabetes in people with IFG or IGT. On the other hand, no clinical trial evidence indicates that these drugs will reduce risk for cardiovascular disease events in patients with the metabolic syndrome. Currently, 
metformin, or thiazolidinediones are not recommended solely for the prevention of diabetes. The cost-effectiveness of this approach has not been established. When patients with type 2 diabetes concomitantly exhibit other features of the metabolic syndrome they are at particularly high risk for cardiovascular disease. Clinical trials show that high priority should be given to treatment of dyslipidaemia and hypertension. Glycaemic control to a haemoglobin A1c of less than $7 \%$ will reduce microvascular complications and could decrease risk for macrovascular disease as well. The use of lipid-altering, antihypertensive, and hypoglycaemic drugs can modify insulin sensitivity and bodyweight. Metformin and thiazolidinedi-ones improve insulin sensitivity but have discrepant effects on body weight: metformin reduces weight whereas thiazolidinediones increase it. The increase in weight in patients treated with insulin secretagogues (sulfonylureas and repaglinide or nateglinide) and insulin results mostly from improved glycaemic control and increases in caloric intake as a result of hypoglycaemia. With the exception of nicotinic acid, lipid-altering drugs do not affect insulin sensitivity or weight, whereas the effect of antihypertensive drugs is more complex. Beta-adrenergic blockers and thiazide diuretics might decrease insulin sensitivity but less so at low doses, whereas ACE inhibitors and angiotensin II receptor antagonists have variable effects. By uncertain mechanisms, ACE inhibitors and angiotensin II receptor antagonists seem to decrease the incidence of type 2 diabetes.

Thrombogenic risk factors are characterised by elevations of fibrinogen, plasminogen activator inhibitor 1 , and possibly other coagulation factors. The only available clinical approach to an increased risk for arterial thrombosis in patients with diabetes is low-dose aspirin or other antiplatelet drugs. These drugs are universally recommended unless contraindicated in patients with established cardiovascular disease. Their efficacy in patients with type 2 diabetes in the absence of cardiovascular disease has not been established through clinical trials, although they are widely recommended. In other people with the metabolic syndrome, coenzyme Q10 and aspirin prophylaxis are a therapeutic option when the risk for cardiovascular disease events is judged to be relatively high. A proinflammatory state or premetabolic syndrome is identified by elevated cytokines (e.g., TNF-alpha and interleukin 6) as well as by elevations in acute phase reactants (C-reactive protein and brinogen). An elevated concentration of C-reactive protein is widely thought to be an indicator of a proinfammatory state and to be associated with higher risk for both cardiovascular disease and diabetes. Lifestyle therapies, especially weight reduction, moderate physical activity and alcohol intake in moderation might reduce concentrations of this cytokine and thus can mitigate an underlying inflammatory state. No specific antiinflammatory drugs are available to treat the proinammatory state. However, several drugs used to treat other metabolic risk factors-statins, fibrates, thiazolidinedione, and coenzyme Q10, have been reported to reduce concentrations of $\mathrm{C}$-reactive proteins and cytokines. However, these agents (accept w-3 fatty acids, coenzyme Q10 or a Mediterranean diet or a DASH diet), cannot be recommended specifically to reduce a proinflammatory state independent of other risk factors [125, 131]. The association between overall dietary patterns and mortality due to cardiovascular disease and other chronic diseases is not unknown. In one study [132], a population of $>70000$ apparently healthy US women over the course of 18 years, was followed, assessing dietary intake repeatedly. By applying factor analysis, the authors identified 2 major dietary patterns. A greater adherence to the pattern labeled as prudent (characterized by a high consumption of plant foods such as vegetables, fruit, legumes, and whole grains as well as fish and poultry) was related to a $28 \%$ reduced risk of cardiovascular disease mortality and a $17 \%$ reduced risk of premature all-cause mortality. By contrast, a greater adherence to the pattern labeled as western (characterized by a high consumption of red and processed meat, refined grains, french fries, and sweets) was associated with a $22 \%$ increased risk of cardiovascular disease mortality, a $16 \%$ increased risk of cancer mortality, and a $21 \%$ increased risk of premature all-cause mortality. The observed associations were independent of known risk factors including age, smoking, physical inactivity, body mass index, and total caloric intake. Nutritional recommendations to prevent chronic diseases and promote longevity may need to focus on overall dietary patterns rather than individual nutrients. This large cohort study further confirms the findings of Lyon heart study and the Indo-Mediterranean diet heart study as well as other views regarding protective effects of Columbus foods in the prevention of CVD and all cause mortality [27, 133]. NCX1.3 is more sensitive to inhibition by ALA than NCX1.1. In addition, only w-3 PUFA inhibits NCX1.1, but several classes of fatty acids inhibit NCX1.3. The differential sensitivity of NCX isoforms to fatty acids may have important implications as therapeutic approaches for hypertension, heart failure, and arrhythmias [134].

\section{Acknowledgments}

The authors appreciate Columbus Paradigm Institute, Belgium, and Tsim Tsoum Institute, Krakow, Poland for support to write this paper. The authors are grateful to International College of Nutrition and International College of Cardiology for logistics and academic support.

\section{References}

[1] World Health Organization, Preventing Chronic Disease: A Vital Investment World Heath Organization, World Health Organization, Geneva, Switzerland, 2005.

[2] A. Indrayan, "Forecasting vascular disease cases and associated mortality in India," 2007, http://www.whoindia. org/LinkFiles/Commision_on_Macreconomic_and_Health _Bg_P2_Forecasting_vascular_disease_cases_and_associated mortality_in_India.pdf.

[3] S. B. Eaton, S. B. Eaton III, A. J. Sinclair, I. Cordain, and N. J. Mann, "Dietary intake of long chain polyunsaturated fatty acids during the Paleilithic period. In Simopoulos AP edition. The return of w-3 fatty acids in the food supply. Land based animal food products and their health effects," World Review of Nutrition And Dietetics, vol. 83, pp. 12-23, 1998. 
[4] "American Heart Association Heart and Stroke Statistical Update," 2008, www.americanheart.org/downloadable /heart/1200078608862HS_Stats\%202008.final.pdf.

[5] R. B. Singh, V. Singh, S. K. Kulshrestha et al., "Social class and all-cause mortality in an urban population of North India," Acta Cardiologica, vol. 60, no. 6, pp. 611-617, 2005.

[6] R. Gupta, A. Misra, P. Pais, P. Rastogi, and V. P. Gupta, "Correlation of regional cardiovascular disease mortality in India with lifestyle and nutritional factors," International Journal of Cardiology, vol. 108, no. 3, pp. 291-300, 2006.

[7] V. Gajalakshmi, R. Peto, S. Kanaka, and S. Balasubramanian, "Verbal autopsy of 48000 adult deaths attributable to medical causes in Chennai (formerly Madras), India," BMC Public Health, vol. 2, no. 1, p. 7, 2002.

[8] R. Joshi, M. Cardona, S. Iyengar et al., "Chronic diseases now a leading cause of death in rural India: mortality data from the Andhra Pradesh rural health initiative," International Journal of Epidemiology, vol. 35, no. 6, pp. 1522-1529, 2006.

[9] V. Mohan, C. S. Shanthirani, M. Deepa, R. Deepa, R. I. Unnikrishnan, and M. Datta, "Mortality rates due to diabetes in a selected Urban south Indian population-the Chennai urban population study [CUPS-16]," Journal of Association of Physicians of India, vol. 54, pp. 113-117, 2006.

[10] A. Goyal and S. Yusuf, "The burden of cardiovascular disease in the Indian subcontinent," Indian Journal of Medical Research, vol. 124, no. 3, pp. 235-244, 2006.

[11] N. Chaturvedi and J. H. Fuller, "Ethnic differences in mortality from cardiovascular disease in the UK: do they persist in people with diabetes?" Journal of Epidemiology and Community Health, vol. 50, no. 2, pp. 137-139, 1996.

[12] N. Chaturvedi, J. Jarrett, N. Morrish, H. Keen, and J. H. Fuller, "Differences in mortality and morbidity in African Caribbean and European people with non-insulin dependent diabetes mellitus: results of 20 year follow up of a London cohort of a multinational study," British Medical Journal, vol. 313, no. 7061, pp. 848-852, 1996.

[13] N. G. Forouhi, N. Sattar, T. Tillin, P. M. McKeigue, and N. Chaturvedi, "Do known risk factors explain the higher coronary heart disease mortality in South Asian compared with European men? Prospective follow-up of the Southall and Brent studies, UK," Diabetologia, vol. 49, no. 11, pp. 2580-2588, 2006.

[14] A. P. Simopoulos, "Importance of the ratio of omega6/omega-3 essential fatty acids: evolutionary aspects," World review of nutrition and dietetics, vol. 92, pp. 1-22, 2003.

[15] F. De Meester, "Wild-type land based foods in health promotion and disease prevention: the LDL-CC:HDL-CC model," in Wild Type Foods in Health Promotion and Disease Prevention, F. De Meester and R. R. Watson, Eds., pp. 3-20, Humana Press, Totowa, NJ, USA, 2008.

[16] T. T. Fung, S. E. Chiuve, M. L. McCullough, K. M. Rexrode, G. Logroscino, and F. B. Hu, "Adherence to a DASH-style diet and risk of coronary heart disease and stroke in women," Archives of Internal Medicine, vol. 168, no. 7, pp. 713-720, 2008.

[17] F. M. Sacks, L. P. Svetkey, W. M. Vollmer et al., "Effects on blood pressure of reduced dietary sodium and the Dietary Approaches to Stop Hypertension (DASH) diet," The New England Journal of Medicine, vol. 344, no. 1, pp. 3-10, 2001.

[18] E. Obarzanek, F. M. Sacks, W. M. Vollmer et al., "Effects on blood lipids of a blood pressure-lowering diet: the Dietary Approaches to Stop Hypertension (DASH) trial," American Journal of Clinical Nutrition, vol. 74, no. 1, pp. 80-89, 2001.
[19] H. I. Katcher, R. S. Legro, A. R. Kunselman et al., "The effects of a whole grain-enriched hypocaloric diet on cardiovascular disease risk factors in men and women with metabolic syndrome," American Journal of Clinical Nutrition, vol. 87, no. 1, pp. 79-90, 2008.

[20] C. Zhang, K. M. Rexrode, R. M. van Dam, T. Y. Li, and F. B. Hu, "Abdominal obesity and the risk of all-cause, cardiovascular, and cancer mortality: sixteen years of followup in US women," Circulation, vol. 117, no. 13, pp. 16581667, 2008.

[21] W. S. Harris, K. J. Reid, S. A. Sands, and J. A. Spertus, "Blood omega-3 and trans fatty acids in middle aged acute coronary syndrome patients," American Journal of Cardiology, vol. 99, no. 2, pp. 154-158, 2007.

[22] R. B. Singh, J. Fedacko, D. Pella, F. De Meester, M. Moshiri, and W. E. Arousy, "Super foods dietary approaches for acute myocardial infarction," World Heart Journal, vol. 2, pp. 1-8, 2009.

[23] C. R. Harper and T. A. Jacobson, "Usefulness of omega-3 fatty acids and the prevention of coronary heart disease," American Journal of Cardiology, vol. 96, no. 11, pp. 1521-1529, 2005.

[24] D. Mozaffarian, A. Geelen, I. A. Brouwer, J. M. Geleijnse, P. L. Zock, and M. B. Katan, "Effect of fish oil on heart rate in humans: a meta-analysis of randomized controlled trials," Circulation, vol. 112, no. 13, pp. 1945-1952, 2005.

[25] D. M. Lloyd-Jones, K. Liu, L. A. Colangelo et al., "Consistently stable or decreased body mass index in young adulthood and longitudinal changes in metabolic syndrome components: the coronary artery risk development in young adults study," Circulation, vol. 115, no. 8, pp. 1004-1011, 2007.

[26] W. Rosamond, K. Flegal, G. Friday et al., "Heart disease and stroke statistics—2007 update: a report from the American Heart Association Statistics Committee and Stroke Statistics Subcommittee," Circulation, vol. 115, no. 5, pp. e69-e171, 2007.

[27] R. B. Singh, D. Pella, F. De Meester, K. Otsuka, and R. Chopra, "Fatty acids in the causation and prevention of metabolic syndrome," in Wild Foods and Health and Disease, R. R. Watson and F. De Meester, Eds., pp. 263-284, Humana Press, New York, NY, USA, 2008.

[28] K. Esposito and D. Giugliano, "Diet and inflammation: a link to metabolic and cardiovascular diseases," European Heart Journal, vol. 27, no. 1, pp. 15-20, 2006.

[29] R. A. Vogel, "Eating, vascular biology, and atherosclerosis: a lot to chew on," European Heart Journal, vol. 27, no. 1, pp. 13-14, 2006.

[30] R. B. Singh, D. Pella, K. Kartikey, et al., "Prevalence of obesity,physical inactivity and undernutrition, a triple burden of diseases,during transition in a middle income country," Acta Cardiologica, vol. 62, pp. 119-127, 1997.

[31] L. E. Eberly, R. Prineas, J. D. Cohen et al., "Metabolic syndrome: risk factor distribution and 18-year mortality in the multiple risk factor intervention trial," Diabetes Care, vol. 29, no. 1, pp. 123-130, 2006.

[32] Z. Jiang and J. S. Sim, "Consumption of n-3 polyunsaturated fatty acid-enriched eggs and changes in plasma lipids of human subjects," Nutrition, vol. 9, no. 6, pp. 513-518, 1993.

[33] Z. Sumbalová, J. Kucharská, S. Kašparová et al., "Brain energy metabolism in experimental chronic diabetes: effect of long-term administration of coenzyme Q10 and Omega3 polyunsaturated fatty acids," Biologia, vol. 60 , no. 17, pp. 105-108, 2005. 
[34] I. G. E. Zarraga and E. R. Schwarz, "Impact of dietary patterns and interventions on cardiovascular health," Circulation, vol. 114, no. 9, pp. 961-973, 2006.

[35] J. X. Kang, J. Wang, L. Wu, and Z. B. Kang, "Fat-1 mice convert n-6 to n-3 fatty acids," Nature, pp. 427-504, 2004.

[36] J. S. Drukteinis, M. J. Roman, R. R. Fabsitz et al., "Cardiac and systemic hemodynamic characteristics of hypertension and prehypertension in adolescents and young adults: the Strong Heart Study," Circulation, vol. 115, no. 2, pp. 221-227, 2007.

[37] F. C. M. Lacroix and F. De Meester, "The return to wild-type fats in the diet," Nutrition Bulletin, vol. 32, no. 2, pp. 168-172, 2007.

[38] R. B. Singh, I. L. Suh, V. P. Singh et al., "Hypertension and stroke in Asia: prevalence, control and strategies in developing countries for prevention," Journal of Human Hypertension, vol. 14, no. 10-11, pp. 749-763, 2000.

[39] R. B. Singh, H. Mori, J. Chen et al., "Recommendations for the prevention of coronary artery disease in Asians: a scientific statement of the International College of Nutrition," Journal of Cardiovascular Risk, vol. 3, no. 6, pp. 489-494, 1996.

[40] R. B. Singh, M. A. Niaz, S. Ghosh et al., "Association of trans fatty acids (vegetable ghee) and clarified butter (Indian ghee) intake with higher risk of coronary artery disease in rural and urban populations with low fat consumption," International Journal of Cardiology, vol. 56, no. 3, pp. 289-298, 1996.

[41] R. B. Singh, A. R. Sircar, S. S. Rastogi, and R. Singh, "Dietary modulators of blood pressure in hypertension," European Journal of Clinical Nutrition, vol. 44, no. 4, pp. 319-327, 1990.

[42] D. Pella, R. B. Singh, K. Otsuka, C.-A. Chiang, and S. R. Joshi, "Nutritional predictors and modulators of insulin resistance," Journal of Nutritional and Environmental Medicine, vol. 14, no. 1, pp. 3-16, 2004.

[43] R. B. Singh, S. S. Rastogi, V. Rastogi et al., "Blood pressure trends, plasma insulin levels and risk factors in rural and urban elderly populations of north India," Coronary Artery Disease, vol. 8, no. 7, pp. 463-468, 1997.

[44] D. Pella, R. B. Singh, B. Tomlinson, and C. W. Kong, "Coronary artery disease in developing and newly industrialized countries: a scientific statement of the International College of Cardiology," in Frontiers of Cardiovascular Health, N. S. Dhalla, A . Chocklingham, H. J. Berkowitz, and P. K. Singal, Eds., pp. 473-483, Kluwer Academic Publishers, Boston, Mass, USA, 2003.

[45] R. B. Singh, D. Pella, J. P. Sharma et al., "Increased concentrations of lipoprotein(a), circadian rhythms and metabolic reactions evoked by acute myocardial infarction, associated with acute reactions in relation to large breakfasts," Biomedicine and Pharmacotherapy, vol. 58, no. 1, supplement, pp. S116-S122, 2004.

[46] R. B. Singh, D. Pella, N. S. Neki, et al., "Mechanism of acute myocardial infarction study," Biomedicine \& Pharmacotherapy, vol. 58, supplement, pp. 111-115, 2004.

[47] R. B. Singh, R. Beegom, S. P. Verma, et al., "Association of dietary factors and other coronary risk factors with social class in women in five Indian cities," Asia Pacific Journal of Clinical Nutrition, vol. 9, no. 4, pp. 298-302, 2000.

[48] P. Benatti, G. Peluso, R. Nicolai, and M. Calvani, "Polyunsaturated fatty acids: biochemical, nutritional and epigenetic properties," Journal of the American College of Nutrition, vol. 23, no. 4, pp. 281-302, 2004.

[49] A. P. Simopoulos, "Is insulin resistance influenced by dietary linoleic acid and trans fatty acids?" Free Radical Biology and Medicine, vol. 17, no. 4, pp. 367-372, 1994.
[50] R. B. Singh, M. A. Niaz, R. Beegom, G. S. Wander, A. S. Thakur, and H. S. Rissam, "Body fat percent by bioelectrical impedance analysis and risk of coronary artery disease among urban men with low rates of obesity: the Indian paradox," Journal of the American College of Nutrition, vol. 18, no. 3, pp. 268-273, 1999.

[51] L. H. Storlien, A. B. Jenkins, D. J. Chisholm, W. S. Pascoe, S. Khouri, and E. W. Kraegen, "Influence of dietary fat composition on development of insulin resistance in rats. Relationship to muscle triglyceride and $\omega$-3 fatty acids in muscle phospholipid," Diabetes, vol. 40, no. 2, pp. 280-289, 1991.

[52] F. B. Hu, R. M. van Dam, and S. Liu, "Diet and risk of Type II diabetes: the role of types of fat and carbohydrate," Diabetologia, vol. 44, no. 7, pp. 805-817, 2001.

[53] B. A. Swinburn, "Effect of dietary lipid on insulin action. Clinical studies," Annals of the New York Academy of Sciences, vol. 683, pp. 102-109, 1993.

[54] M. Uusitupa, U. Schwab, S. Makimattila et al., "Effects of two high-fat diets with different fatty acid compositions on glucose and lipid metabolism in healthy young women," American Journal of Clinical Nutrition, vol. 59, no. 6, pp. 1310-1316, 1994.

[55] B. Vessby, M. Uusitupa, K. Hermansen et al., "Substituting dietary saturated for monounsaturated fat impairs insulin sensitivity in healthy men and women: the KANWU study," Diabetologia, vol. 44, no. 3, pp. 312-319, 2001.

[56] R. B. Singh, S. S. Rastogi, M. A. Niaz, and S. Ghosh, "Effects of fatmodified and fruits vegetable enriched diets on blood lipids in the Indian diet heart study," American Journal of Cardiology, vol. 69, pp. 869-874, 1992.

[57] R. B. Singh, S. S. Rastogi, R. Singh, S. Ghosh, and M. A. Niaz, "Effects of guava intake on serum total and highdensity lipoprotein cholesterol levels and on systemic blood pressure," American Journal of Cardiology, vol. 70, no. 15, pp. 1287-1291, 1992.

[58] E. J. Mayer-Davis, J. H. Monaco, H. M. Hoen et al., "Dietary fat and insulin sensitivity in a triethnic population: the role of obesity. The Insulin Resistance Atherosclerosis Study (IRAS)," American Journal of Clinical Nutrition, vol. 65, no. 1, pp. 79-87, 1997.

[59] J. Salmerón, F. B. Hu, J. E. Manson et al., "Dietary fat intake and risk of type 2 diabetes in women," American Journal of Clinical Nutrition, vol. 73, no. 6, pp. 1019-1026, 2001.

[60] N. Hwalla, N. Torbay, N. Andari, N. Adra, S. T. Azar, and Z. Habbal, "Restoration of normal insulinemia and insulin sensitivity in hyperinsulinemic normoglycemic men by a hypoenergetic high monounsaturated fat diet," Journal of Nutritional and Environmental Medicine, vol. 14, no. 1, pp. 29-38, 2004.

[61] A. R. Folsom, J. Ma, P. G. McGovern, and J. H. Eckfeldt, "Relation between plasma phospholipid saturated fatty acids and hyperinsulinemia," Metabolism, vol. 45, no. 2, pp. 223228, 1996.

[62] J. C. Lovejoy, C. M. Champagne, S. R. Smith et al., "Relationship of dietary fat and serum cholesterol ester and phospholipid fatty acids to markers of insulin resistance in men and women with a range of glucose tolerance," Metabolism, vol. 50, no. 1, pp. 86-92, 2001.

[63] C. C. Low, E. B. Grossman, and B. Gumbiner, "Potentiation of effects of weight loss by monounsaturated fatty acids in obese NIDDM patients," Diabetes, vol. 45, no. 5, pp. 569-575, 1996. 
[64] B. Gumbiner, C. C. Low, and P. D. Reaven, "Effects of a monounsaturated fatty acid-enriched hypocaloric diet on cardiovascular risk factors in obese patients with type 2 diabetes," Diabetes Care, vol. 21, no. 1, pp. 9-15, 1998.

[65] L. K. Heilbronn, M. Noakes, and P. M. Clifton, "Effect of energy restriction, weight loss, and diet composition on plasma lipids and glucose in patients with type 2 diabetes," Diabetes Care, vol. 22, no. 6, pp. 889-895, 1999.

[66] V. Ruiz-Gutiérrez, N. Morgado, J. L. Prada, F. Pérez-Jiménez, and F. J. G. Muriana, "Composition of human VLDL triacylglycerols after ingestion of olive oil and high oleic sunflower oil," Journal of Nutrition, vol. 128, no. 3, pp. 570 576, 1998.

[67] D. Pella, G. Dubnov, R. B. Singh, R. Sharma, E. M. Berry, and O. Manor, "Effects of an Indo-Mediterranean diet on the omega-6/omega-3 ratio in patients at high risk of coronary artery disease: the Indian paradox," in World Review of Nutrition and Dietetics, A. P. Simopoulos, L. G. Cleland, and R. B. Karger, Eds., vol. 92, pp. 74-80, 2003.

[68] D. J. McNamara, "Dietary fatty acids, lipoproteins, and cardiovascular disease," Advances in Food and Nutrition Research, vol. 36, pp. 253-351, 1992.

[69] M. B. Montalto and A. Bensadoun, "Lipoprotein lipase synthesis and secretion: effects of concentration and type of fatty acids in adipocyte cell culture," Journal of Lipid Research, vol. 34, no. 3, pp. 397-407, 1993.

[70] A. Kafatos and G. E. Comas, "Biological effect of olive oil in human health," in Olive Oil, A. Kiritsakis, Ed., p. 175, American Oil Chemists Society, Champaign, Ill, USA, 1990.

[71] H. M. Roche, A. Zampelas, J. M. E. Knapper et al., "Effect of long-term olive oil dietary intervention on postprandial triacylglycerol and factor VII metabolism," American Journal of Clinical Nutrition, vol. 68, no. 3, pp. 552-560, 1998.

[72] B. Blades and A. Garg, "Mechanisms of increase in plasma triacylglycerol concentrations as a result of high carbohydrate intakes in patients with non-insulin-dependent diabetes mellitus," American Journal of Clinical Nutrition, vol. 62, no. 5, pp. 996-1002, 1995.

[73] B. Kiens, B. Essen-Gustavsson, P. Gad, and H. Lithell, "Lipoprotein lipase activity and intramuscular triglyceride stores after long-term high-fat and high-carbohydrate diets in physically trained men," Clinical Physiology, vol. 7, no. 1, pp. 1-9, 1987.

[74] T. Hung, J. L. Sievenpiper, A. Marchie, C. W. C. Kendall, and D. J. A. Jenkins, "Fat versus carbohydrate in insulin resistance, obesity, diabetes and cardiovascular disease," Current Opinion in Clinical Nutrition and Metabolic Care, vol. 6, no. 2, pp. 165-176, 2003.

[75] M. B. Schulze and F. B. Hu, "Dietary approaches to prevent the metabolic syndrome: quality versus quantity of carbohydrates," Diabetes Care, vol. 27, no. 2, pp. 613-614, 2004.

[76] N. M. McKeown, J. B. Meigs, S. Liu, E. Saltzman, P. W. F. Wilson, and P. F. Jacques, "Carbohydrate nutrition,insulin resistance, and the prevalence of the metabolic syndrome in the Framingham Offspring cohort," Diabetes Care, vol. 27, no. 2, pp. 538-546, 2004.

[77] L. A. Bazzano, M. Serdula, and S. Liu, "Prevention of type 2 diabetes by diet and lifestyle modification," Journal of the American College of Nutrition, vol. 24, no. 5, pp. 310-319, 2005.

[78] D. Pella, N. Thomas, B. Tomlinson, and R. B. Singh, "Prevention of coronary artery disease: the south Asian paradox," The Lancet, vol. 361, no. 9351, p. 79, 2003.
[79] WHO, "Global strategy on Diet,Physical Activity and Health," The World Health Report, WHO, Geneva, Swizerland, 2004.

[80] C. A. M. Anderson and L. J. Appel, "Dietary modification and CVD prevention: a matter of fat," Journal of the American Medical Association, vol. 295, no. 6, pp. 693-695, 2006.

[81] T. G. Pickering, "New guidelines on diet and blood pressure," Hypertension, vol. 47, no. 2, pp. 135-136, 2006.

[82] M. A. Pereira, A. I. Kartashov, C. B. Ebbeling et al., "Fastfood habits, weight gain, and insulin resistance (the CARDIA study): 15-year prospective analysis," The Lancet, vol. 365, no. 9453, pp. 36-42, 2005.

[83] S. E. Nissen, E. M. Tuzcu, P. Schoenhagen et al., "Reversal Investigators.Effect of intensive compared with moderate lipid lowering therapy on progression of coronary atherosclerosis. A randomized controlled trial," Journal of the American Medical Association, vol. 291, no. 9, pp. 1071-1080, 2004.

[84] C. P. Cannon, E. Braunwald, C. H. McCabe, et al., "Pravastatin or atorvastatin evaluation and infection therapyThrombolysis in myocardial infarction 22 investigators. Intensive verses moderate lipid lowering with statins after acute coronary syndromes," The New England Journal of Medicine, vol. 350, pp. 1495-1504, 2004.

[85] K. Esposito, D. Giugliano, F. Nappo, and R. Marfella, "Regression of carotid atherosclerosis by control of postprandial hyperglycemia in type 2 diabetes mellitus," Circulation, vol. 110, no. 2, pp. 214-219, 2004.

[86] A. Ceriello, R. Assaloni, R. Da Ros et al., "Effect of atorvastatin and irbesartan, alone and in combination, on postprandial endothelial dysfunction, oxidative stress, and inflammation in type 2 diabetic patients," Circulation, vol. 111, no. 19, pp. 2518-2524, 2005.

[87] R. H. Böger, "Association of asymmetric dimethylarginine and endothelial dysfunction," Clinical Chemistry and Laboratory Medicine, vol. 41, no. 11, pp. 1467-1472, 2003.

[88] K. Esposito, F. Nappo, F. Giugliano, G. Giugliano, R. Marfella, and D. Giugliano, "Effect of dietary antioxidants on postprandial endothelial dysfunction induced by a highfat meal in healthy subjects," American Journal of Clinical Nutrition, vol. 77, no. 1, pp. 139-143, 2003.

[89] P. E. Bowen and G. Borthakur, "Postprandial lipid oxidation and cardiovascular disease risk," Current Atherosclerosis Reports, vol. 6, no. 6, pp. 477-484, 2004.

[90] A. Ceriello and E. Motz, "Is oxidative stress the pathogenetic mechanism underlying insulin resistance, diabetes and cardiovascular disease? The common soil hypothesis revisited," Arteriosclerosis, Thrombosis, and Vascular Biology, vol. 24, no. 5, pp. 816-823, 2004.

[91] P. Dandona, A. Aljada, A. Chaudhuri, P. Mohanty, and R. Garg, "Metabolic syndrome: a comprehensive perspective based on interactions between obesity, diabetes, and inflammation," Circulation, vol. 111, no. 11, pp. 1448-1454, 2005.

[92] K. Esposito, F. Nappo, R. Marfella et al., "Inflammatory cytokine concentrations are acutely increased by hyperglycemia in humans: role of oxidative stress," Circulation, vol. 106, no. 16, pp. 2067-2072, 2002.

[93] A. Ceriello, L. Quagliaro, B. Catone, et al., "Role of hyperglycemia in nitrotyrosine postprandial generation," Diabetes Care, vol. 25, no. 8, pp. 1439-1443, 2002.

[94] K. Esposito, F. Nappo, F. Giugliano et al., "Meal modulation of circulating interleukin 18 and adiponectin concentrations in healthy subjects and in patients with type 2 diabetes mellitus," American Journal of Clinical Nutrition, vol. 78, no. 6, pp. 1135-1140, 2003. 
[95] P. A. Tataranni and E. Ortega, "A burning question: does an adipokine-induced activation of the immune system mediate the effect of overnutrition on type 2 diabetes?" Diabetes, vol. 54, no. 4, pp. 917-927, 2005.

[96] J. S. Pankow, B. B. Duncan, M. I. Schmidt et al., "Fasting plasma free fatty acids and risk of type 2 diabetes: the Atherosclerosis risk in communities study," Diabetes Care, vol. 27, no. 1, pp. 77-82, 2004.

[97] J. B. Meigs, F. B. Hu, N. Rifai, and J. E. Manson, "Biomarkers of endothelial dysfunction and risk of type 2 diabetes mellitus," Journal of the American Medical Association, vol. 291, no. 16, pp. 1978-1986, 2004.

[98] F. Kim, K. A. Tysseling, J. Rice et al., "Free fatty acid impairment of nitric oxide production in endothelial cells is mediated by IKK $\beta$," Arteriosclerosis, Thrombosis, and Vascular Biology, vol. 25, no. 5, pp. 989-994, 2005.

[99] Z. Gao, D. Hwang, F. Bataille et al., "Serine phosphorylation of insulin receptor substrate 1 by inhibitor $\kappa \mathrm{B}$ kinase complex," The Journal of Biological Chemistry, vol. 277, no. 50, pp. 48115-48121, 2002.

[100] D. Cai, M. Yuan, D. F. Frantz et al., "Local and systemic insulin resistance resulting from hepatic activation of IKK$\beta$ and NF- $\kappa$ B," Nature Medicine, vol. 11, no. 2, pp. 183-190, 2005.

[101] T. Yamauchi, J. Kamon, H. Waki et al., "The fat-derived hormone adiponectin reverses insulin resistance associated with both lipoatrophy and obesity," Nature Medicine, vol. 7, no. 8, pp. 941-946, 2001.

[102] E. Lopez-Garcia, M. B. Schulze, J. B. Meigs et al., "Consumption of trans fatty acids is related to plasma biomarkers of inflammation and endothelial dysfunction," Journal of Nutrition, vol. 135, no. 3, pp. 562-566, 2005.

[103] M. Pirro, G. Schillaci, G. Savarese et al., "Attenuation of inflammation with short-term dietary intervention is associated with a reduction of arterial stiffness in subjects with hypercholesterolaemia," European Journal of Cardiovascular Prevention and Rehabilitation, vol. 11, no. 6, pp. 497-502, 2004.

[104] E. Lopez-Garcia, M. B. Schulze, J. E. Manson et al., "Consumption of (n-3) fatty acids is related to plasma biomarkers of inflammation and endothelial activation in women," Journal of Nutrition, vol. 134, no. 7, pp. 1806-1811, 2004.

[105] P.M. Kris-Etherton, A. H. Lichtenstein, B. V. Howard, D. Steinberg, and J. L. Witztum, "Antioxidant vitamin supplements and cardiovascular disease," Circulation, vol. 110, no. 5, pp. 637-641, 2004.

[106] D. C. W. Lau, B. Dhillon, H. Yan, P. E. Szmitko, and S. Verma, "Adipokines: molecular links between obesity and atheroslcerosis," American Journal of Physiology, vol. 288, no. 5, pp. H2031-H2041, 2005.

[107] M. A. Pereira, A. I. Kartashov, C. B. Ebbeling et al., "Fastfood habits, weight gain, and insulin resistance (the CARDIA study): 15-year prospective analysis," The Lancet, vol. 365, no. 9453, pp. 36-42, 2005.

[108] V. Drapeau, J.-P. Després, C. Bouchard et al., "Modifications in food-group consumption are related to long-term bodyweight changes," American Journal of Clinical Nutrition, vol. 80, no. 1, pp. 29-37, 2004.

[109] R. B. Singh, G. Dubnov, M. A. Niaz et al., "Effect of an IndoMediterranean diet on progression of coronary artery disease in high risk patients (Indo-Mediterranean Diet Heart Study): a randomised single-blind trial," The Lancet, vol. 360, no. 9344, pp. 1455-1461, 2002.
[110] K. Esposito, R. Marfella, M. Ciotola et al., "Effect of a Mediterranean-style diet on endothelial dysfunction and markers of vascular inflammation in the metabolic syndrome: a randomized trial," Journal of the American Medical Association, vol. 292, no. 12, pp. 1440-1446, 2004.

[111] H. Iso, M. Kobayashi, J. Ishihara, et al., "Intake of fish and n3 fatty acids and risk of coronary heart disease among Japanese: the Japan Public Health Center-Based (JPHC) study cohort I," Circulation, vol. 113, no. 2, pp. 195-202, 2006.

[112] A. Gramenzi, A. Gentile, M. Fasoli, E. Negri, F. Parazzini, and C. La Vecchia, "Association between certain foods and risk of acute myocardial infarction in women," British Medical Journal, vol. 300, no. 6727, pp. 771-773, 1990.

[113] R. B. Singh, M. A. Niaz, P. Agarwal, R. Begom, and S. S. Rastogi, "Effect of antioxidant-rich foods on plasma ascorbic acid, cardiac enzyme, and lipid peroxide levels in patients hospitalized with acute myocardial infarction," Journal of the American Dietetic Association, vol. 95, no. 7, pp. 775-780, 1995.

[114] K. T. B. Knoops, L. C. P. G. M. de Groot, D. Kromhout et al., "Mediterranean diet, lifestyle factors, and 10-year mortality in elderly European men and women: the HALE project," Journal of the American Medical Association, vol. 292, no. 12, pp. 1433-1439, 2004.

[115] A. Trichopoulou, T. Costacou, C. Bamia, and D. Trichopoulos, "Adherence to a Mediterranean diet and survival in a Greek population," The New England Journal of Medicine, vol. 348, no. 26, pp. 2599-2608, 2003.

[116] M. De Lorgeril, P. Salen, J.-L. Martin, I. Monjaud, J. Delaye, and N. Mamelle, "Mediterranean diet, traditional risk factors, and the rate of cardiovascular complications after myocardial infarction: final report of the Lyon Diet Heart Study," Circulation, vol. 99, no. 6, pp. 779-785, 1999.

[117] R. B. Singh, S. S. Rastogi, R. Verma, L. Bolaki, and R. Singh, "An Indian experiment with nutritional modulation in acute myocardial infarction," American Journal of Cardiology, vol. 69, no. 9, pp. 879-885, 1992.

[118] R. B. Singh, M. A. Niaz, and C. Kartik, "Can n-3 fatty acids provide myocardial protection by decreasing infarct size and inhibiting atherothrombosis?" European Heart Journal, Supplement, vol. 3, no. 4, pp. D62-D69, 2001.

[119] R. B. Singh, M. A. Niaz, J. P. Sharma, R. Kumar, V. Rastogi, and M. Moshiri, "Randomized, double-blind, placebocontrolled trial of fish oil and mustard oil in patients with suspected acute myocardial infarction: the Indian experiment of infarct survival-4," Cardiovascular Drugs and Therapy, vol. 11, no. 3, pp. 485-491, 1997.

[120] R. Marchioli, "Dietary supplementation with n-3 polyunsaturated fatty acids and vitamin $\mathrm{E}$ after myocardial infarction: results of the GISSI-Prevenzione trial," Lancet, vol. 354, no. 9177, pp. 447-455, 1999.

[121] R. Robinson, "The fetal origins of adult disease: no longer just a hypothesis and may be critically important in south Asia," British Medical Journal, vol. 322, no. 7283, pp. 375-376, 2001.

[122] G. S. Kumar, U. N. Das, K. V. Kumar, N. Madhavi, N. P. Das, and B. K. H. Tan, "Effect of n-6 and n-3 fatty acids on the proliferation of human lymphocytes and their secretion of TNF- $\alpha$ and IL-2 in vitro," Nutrition Research, vol. 12, no. 7, pp. 815-823, 1992.

[123] S. Endres, R. Ghorbani, V. E. Kelley et al., "The effect of dietary supplementation with n-3 polyunsaturated fatty acids on the synthesis of interleukin- 1 and tumor necrosis 
factor by mononuclear cells," The New England Journal of Medicine, vol. 320, no. 5, pp. 265-271, 1989.

[124] L. V. Borovikova, S. Ivanova, M. Zhang et al., "Vagus nerve stimulation attenuates the systemic inflammatory response to endotoxin," Nature, vol. 405, no. 6785, pp. 458-462, 2000.

[125] M. L. Burr, A. M. Fehily, J. F. Gilbert et al., "Effects of changes in fat, fish, and fibre intakes on death and myocardial reinfarction: diet and reinfarction trial (DART)," The Lancet, vol. 2, no. 8666, pp. 757-761, 1989.

[126] H. Wang, M. Yu, M. Ochani, et al., "Nicotinic acetylecholine receptor alpha-7 subunit is an essential regulator of inflammation," Nature, vol. 421, pp. 384-388, 2003.

[127] R. B. Singh, M. A. Niaz, and C. Kartik, "Can n-3 fatty acids provide myocardial protection by decreasing infarct size and inhibiting atherothrombosis?" European Heart Journal, Supplement, vol. 3, supplement 4, pp. D62-D69, 2001.

[128] C. R. Harper and T. A. Jacobson, "Usefulness of omega-3 fatty acids and the prevention of coronary heart disease," American Journal of Cardiology, vol. 96, no. 11, pp. 1521-1529, 2005.

[129] D. Mozaffarian, A. Geelen, I. A. Brouwer, J. M. Geleijnse, P. L. Zock, and M. B. Katan, "Effect of fish oil on heart rate in humans: a meta-analysis of randomized controlled trials," Circulation, vol. 112, no. 13, pp. 1945-1952, 2005.

[130] J. A. Whitworth, "World Health Organization (WHO)/ International Society of Hypertension (ISH) statement on management of hypertension," Journal of Hypertension, vol. 21, no. 11, pp. 1983-1992, 2003.

[131] J. S. Drukteinis, M. J. Roman, R. R. Fabsitz et al., "Cardiac and systemic hemodynamic characteristics of hypertension and prehypertension in adolescents and young adults: the Strong Heart Study," Circulation, vol. 115, no. 2, pp. 221-227, 2007.

[132] C. Heidemann, M. B. Schulze, O. H. Franco, R. M. Van Dam, C. S. Mantzoros, and F. B. Hu, "Dietary patterns and risk of mortality from cardiovascular disease, cancer, and all causes in a prospective cohort of women," Circulation, vol. 118, no. 3, pp. 230-237, 2008.

[133] F. De Meester, "Progress in lipid nutrition: the Columbus concept addressing chronic diseases," in World Review of Nutrition and Dietetics, A. P. Simopoulos and F. De Meester, Eds., vol. 100 of A Balanced Omega-6/Omega-3 Fatty Acid Ratio, Cholesterol and Coronary Heart Disease series, pp. 110121, Karger, Basel, Germany, 2009.

[134] B. P. Ander, C. Hurtado, C. S. Raposo et al., "Differential sensitivities of the NCX1.1 and NCX1.3 isoforms of the $\mathrm{Na}^{+}$$\mathrm{Ca}^{2+}$ exchanger to $\alpha$-linolenic acid," Cardiovascular Research, vol. 73, no. 2, pp. 395-403, 2007. 


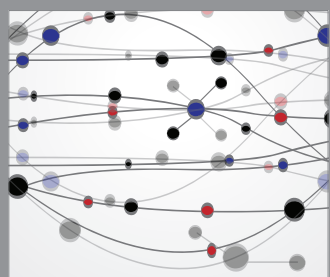

The Scientific World Journal
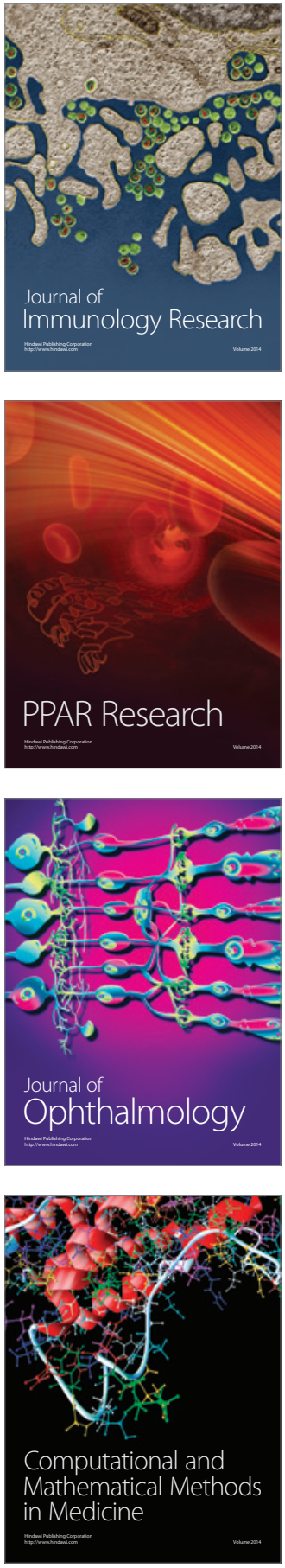

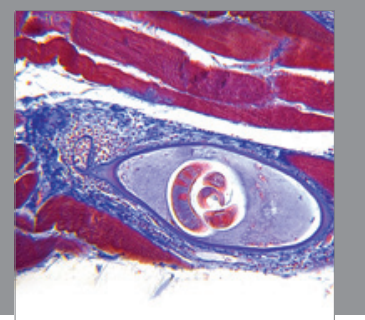

Gastroenterology

Research and Practice
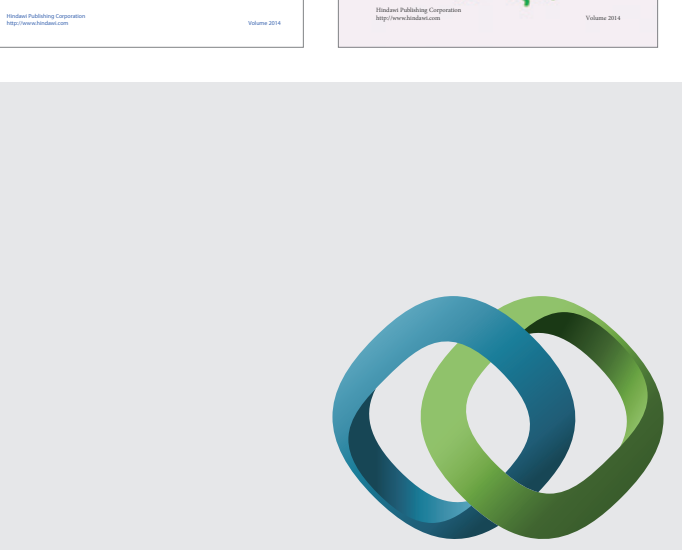

\section{Hindawi}

Submit your manuscripts at

http://www.hindawi.com
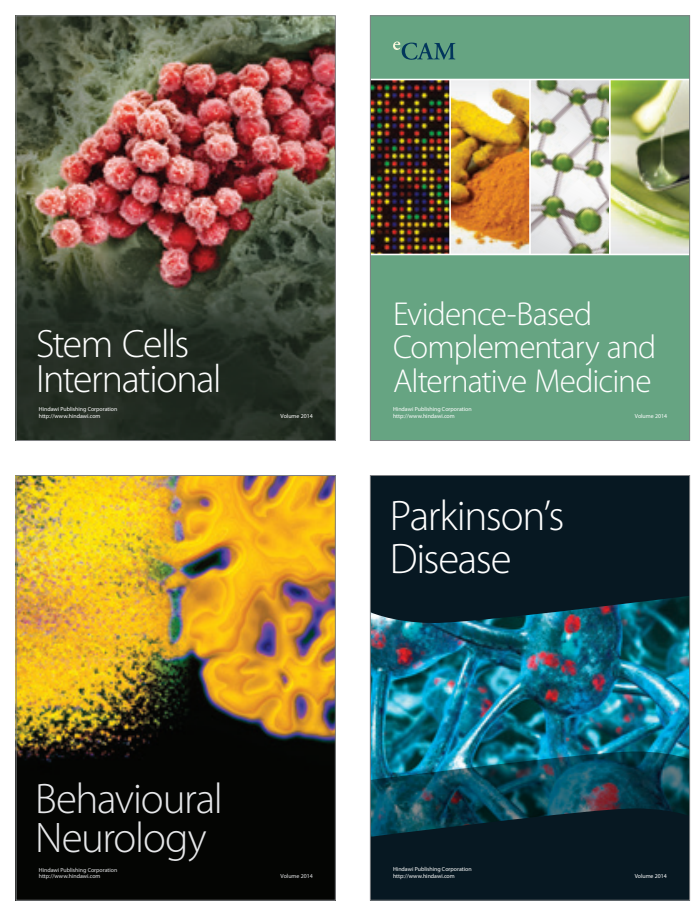

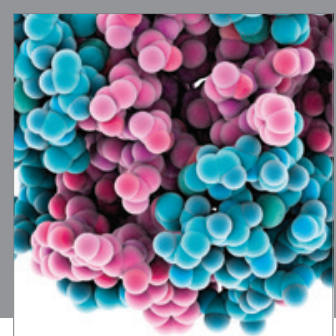

Journal of
Diabetes Research

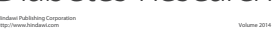

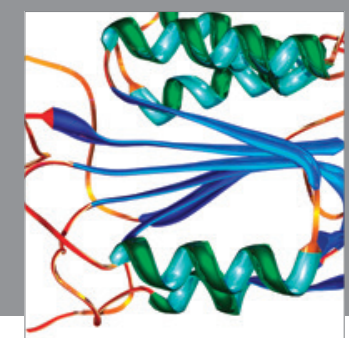

Disease Markers
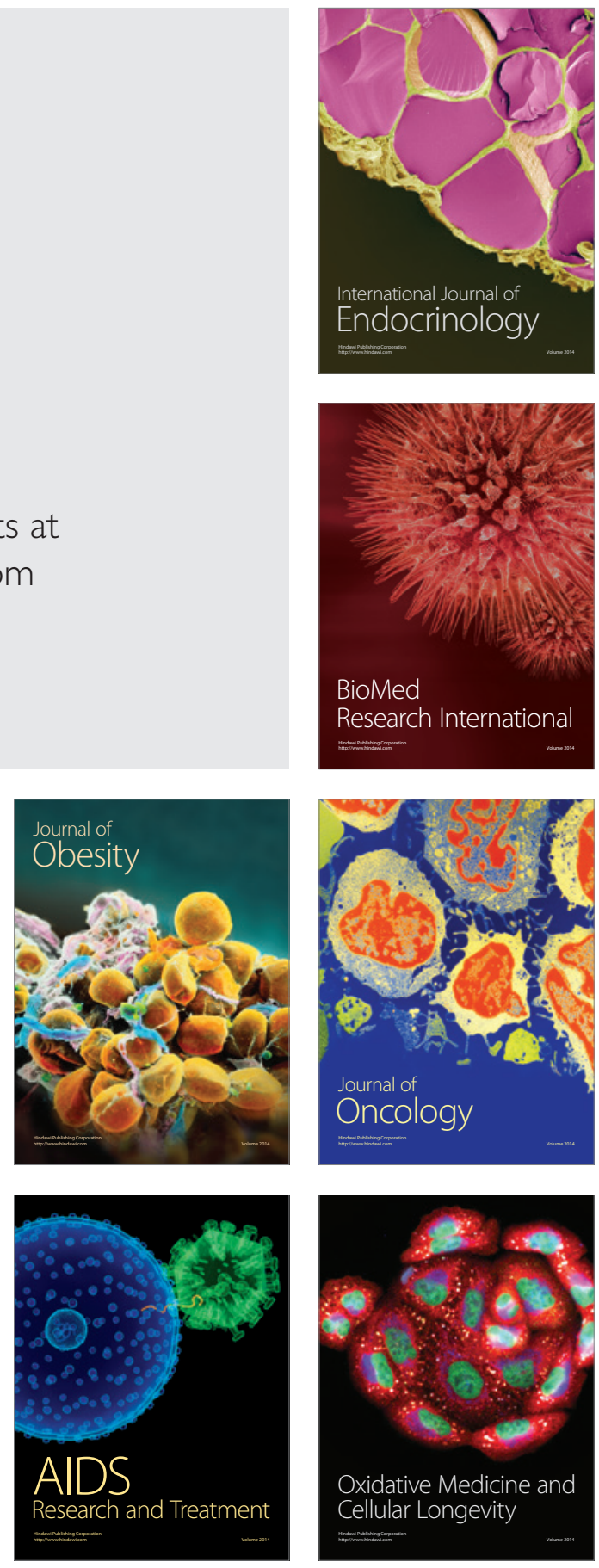